\title{
Product Development in Crowdfunding: Theoretical and Empirical Analysis
}

\author{
Sıdıka Tunç Candoğan \\ UCL School of Management, University College London, London, UK, E14 5AA, sidika.tunc.16@ucl.ac.uk \\ Philipp B. Cornelius \\ Rotterdam School of Management, Erasmus University Rotterdam, 3062 PA Rotterdam, Netherlands, cornelius@rsm.nl \\ Bilal Gokpinar \\ UCL School of Management, University College London, London, UK, E14 5AA, b.gokpinar@ucl.ac.uk \\ Ersin Körpeoğlu \\ UCL School of Management, University College London, London, UK, E14 5AA, e.korpeoglu@ucl.ac.uk
}

Christopher S. Tang

Anderson School of Management, University of California Los Angeles, Los Angeles, CA, 90095, chris.tang@anderson.ucla.edu

\begin{abstract}
Crowdfunding goes beyond raising funds. Entrepreneurs often use crowdfunding to solicit feedback from customers to improve their products, and may therefore prefer to launch crowdfunding campaigns for a basic version of their products with few or no enhancements (i.e., limited features). Yet, customers may not be persuaded by a campaign if a product appears too basic. In view of this trade-off, a key question for an entrepreneur is how far a product should be enhanced before launching a crowdfunding campaign. Analyzing a game-theoretical model and testing its predictions empirically, we study how a product's level of enhancement at campaign launch influences both whether an entrepreneur continues to improve the product during the campaign and whether the campaign is successful. We show that as the product's level of enhancement at campaign launch increases, the likelihood of product improvement during a campaign at first increases (because customers are more likely to provide feedback) and then decreases (because of increased production cost for the entrepreneur). Furthermore, although our theoretical model intuitively predicts that the likelihood of campaign success will always increase when an entrepreneur launches a campaign for a more enhanced product, our empirical analysis shows that the likelihood of campaign success first increases and then decreases. This counterintuitive result may be due to customers being overwhelmed with the complexity of highly enhanced products. Finally, while crowdfunding experts believe that products should be enhanced as much as possible before a campaign, we show that this is not always the best strategy.
\end{abstract}

Key words: product development, entrepreneurship, innovation, natural language processing

\section{Introduction}

The internet has enabled entrepreneurs to use crowdfunding to raise funds from a large number of people for projects ranging from social entrepreneurship to for-profit enterprises. ${ }^{1}$ In addition to crowdfunding being an important financial instrument (e.g., Hu et al. 2015, Belavina et al.

${ }^{1}$ The first recorded crowdfunding on the internet occurred in 1997, when the British band Marillion raised $\$ 60,000$ from fans to fund its North American tour (Masters 2013). 
2020, Chakraborty and Swinney 2021), recent research and practice suggest that it can be used by entrepreneurs (hereafter creators) as a mechanism to involve customers in product development and thus to improve their products during their crowdfunding campaigns (e.g., Mollick 2016, Cornelius and Gokpinar 2020). Customer involvement in product development can lead to significant cost savings (e.g., Thomke and Bell 2001, Loch and Kavadias 2008), so a creator may consider launching a crowdfunding campaign for a basic version of a product (as opposed to a more enhanced version with more features; Althuizen and Chen 2021) to leave room for improvements to it. However, if a product appears too basic, customers may be discouraged from contributing to the campaign, making it less likely that the campaign will be successful (i.e., reach the funding goal). Thus, we study how a creator should choose the product's level of enhancement at campaign launch (hereafter initial enhancement level), taking into account the impact this may have on product improvement and campaign success.

To understand how customers can contribute to product improvement during a crowdfunding campaign, consider the following example from Kickstarter - a global crowdfunding platform that has raised $\$ 5$ billion for entrepreneurs over the last decade (Kickstarter 2021g). In October 2015, the "onomo" team launched a campaign for an innovative bike navigation device, HAIZE (see Figure 1(a); Kickstarter 2021a). During the campaign, customers suggested that HAIZE could include a wristband so that they could also use the product when not on a bike (see Figure 1(b)). In response to suggestions from customers, the creator added a wristband to the product and revised the campaign description accordingly (see Figure 1(c)). In our interview, the creator of HAIZE explained this process as follows: "It's definitely very efficient for that kind of [market] research... the idea, for example, of adding a wristband to the device, it was always like floating... we're not sure if we should do this [or not]... But then, we began to receive very relevant testimonies of people who were having amazing ideas [about a wristband]..."

As this example aptly shows, a creator can make a strategic choice to launch a crowdfunding campaign for a basic product and improve it during the campaign. Since the initial enhancement level of a product can affect whether a creator improves it during the campaign, we start by investigating the following research question: (Q1) How does the initial enhancement level affect the likelihood that the product will be improved during the campaign?

Besides affecting product improvement, the initial enhancement level also influences whether customers pledge money to the campaign, and ultimately whether the campaign is successful. Indeed, experts on Kickstarter campaigns assert that a creator should "have as much done as possible" and "launch [a campaign] as close to production as possible" for a successful campaign (Kickstarter 2021e). The implicit assumption here is that a campaign for a more enhanced product 


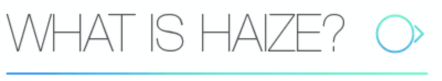

HAIZE is minimalist navigation device for urban cyclists.

It is designed focusing on high quality

materials, style and simplicity.

HAIZE works like a magic compass that, instead of pointing north, points to the destination you set in our app. HAIZE leaves you free to choose your own route through the city.

(a) Initial product.
Francisco Moreno

28 Oct 2015 at 10:06

$\mathrm{Hi}$

Nice product! I hope you can manage to launch it.

Have you think about a wrist strap ? I see potential uses for hiking, trekking or people that like to do treasure hunt waypoint games .... or just discovering a city also walking ...

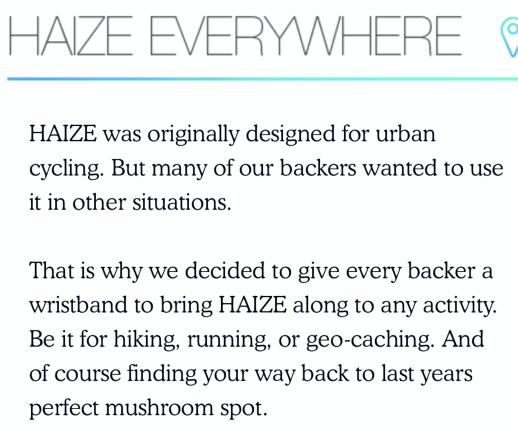

(b) Customer comment.

(c) Product improvement.

Figure 1 Example of initial product, customer comment, and product improvement.

is more likely to be successful, so we investigate this by asking: (Q2) How does the product's initial enhancement level affect the success of the campaign?

Building on the descriptive analyses presented above, and with the aim of generating actionable insights, we study a case in which a creator chooses the optimal initial enhancement level to maximize the profit from the campaign. This allows us to test whether Kickstarter experts are correct in their assertions by investigating the following research question: (Q3) Should a creator enhance the product as much as possible before launching a campaign?

To answer these questions and inspired by the crowdfunding practice and literature (e.g., Hu et al. 2015, Belavina et al. 2020, Chakraborty and Swinney 2021), we build a parsimonious gametheoretical model of a "reward-based, all-or-nothing" crowdfunding campaign that takes into account the creator's product improvement decision. ${ }^{2}$ In such a campaign, a creator solicits funds from customers to finance the launch of a product. To this end, the creator specifies the initial enhancement level of the product (the more enhanced the product is, the greater the number of features it offers), and announces a funding goal and a pledge price. Having considered these, customers then decide whether to pledge money in return for the product, and after pledging, they can make comments to induce the creator to improve the product further. (Customers cannot make comments before pledging; see Kickstarter 2021h.) If the creator sees comments, the creator decides whether to improve the product, and if improvements are made, other potential customers will be seeing the improved product before making pledging decisions. By the end of the campaign, if the total amount pledged reaches the funding goal, the campaign is successful; the creator receives the funds raised, and products are then produced and delivered to customers. If the total amount pledged fails to reach the funding goal, the campaign fails; the creator receives and delivers nothing, and customers are fully refunded.

2 There are also other forms of crowdfunding with respect to the type of reward and type of funding. We refer the reader to Chen et al. (2020) for a review of other forms of crowdfunding. 
We first analyze how the initial enhancement level of a product affects the likelihood of a product being improved during the campaign. Because making an improvement is costly, one might expect that the more enhanced a product is, the less likely the creator will be to make any further improvement to it during the campaign. ${ }^{3}$ Yet, our analysis reveals an opposing effect at play. Specifically, when a product is more enhanced, customers are more likely to pledge and to comment, and hence the creator is more likely to receive a comment that can be used to improve the product. This increases the likelihood of a product being improved during the campaign. However, above a certain level of initial enhancement, the likelihood of product improvements decreases because of the additional costs the creator would incur if implementing them.

To address our second research question, we analyze how the initial enhancement level affects campaign success. Our theoretical model predicts that the likelihood of campaign success increases with the initial enhancement level, albeit at a decreasing rate when the initial enhancement level is high. The reason is that when the product is highly enhanced, customers are already very likely to pledge, so their incentive to pledge is less responsive to a higher initial enhancement level.

We test our theoretical results empirically using a unique large-scale data set from Kickstarter. Our data set contains detailed information about campaign characteristics as well as product descriptions from the beginning and end of the campaigns. To create a measure of enhancement levels of products (i.e., number of features that products offer; Ulrich and Eppinger 2016, Althuizen and Chen 2021), we take advantage of these detailed product descriptions, and use an unsupervised natural language processing technique, latent Dirichlet allocation (LDA; Blei et al. 2003). LDA has been used by marketing and operations scholars for purposes such as extracting product features (Toubia et al. 2019) or generating a measure of a firm's innovation (Bellstam et al. 2020) from textual data. We address possible endogeneity concerns in our empirical analysis by exploiting a policy change on Kickstarter that reduced minimum campaign requirements and thereby provided an exogenous shock to initial enhancement levels.

Our empirical analysis supports the predicted relationship between the initial enhancement level and the likelihood of product improvement. More interestingly, although our theoretical model intuitively predicts that the likelihood of campaign success will increase with the initial enhancement level, we do not observe this empirically. Instead, the likelihood of campaign success first increases with the initial enhancement level but then, counterintuitively, decreases. This discrepancy between our normative theory and the empirical finding hints at the presence of possible behavioral effects. Specifically, when enhancing a product, a creator may end up with a too complex or too advanced

\footnotetext{
${ }^{3}$ For instance, while responding to a customer comment asking for an extra USB port, one creator on Kickstarter explained why it was not feasible to improve the product in this way by saying: "Yes, I would love to have USB3, or USB type C... What you might not know fully is that it is a serious additional cost..." (Kickstarter 2021f).
} 
product, which can be overwhelming for customers (e.g., Mick and Fournier 1998) or can lead to customer anxiety (e.g., Castaño et al. 2008, Goodman and Irmak 2013). Indeed, when we revise our theoretical model to incorporate such behavioral effects, our theoretical predictions become consistent with the empirical results.

Building on these results and to generate prescriptive insights, we investigate whether the creator should enhance the product as much as possible before the campaign. To this end, we analyze a model in which the creator chooses the optimal initial enhancement level to maximize profit. In contrast to what experts on Kickstarter campaigns suggest, we show that a creator should not always enhance a product as much as possible because there is a trade-off between cost savings and chances of success. Specifically, when customer involvement in product development can lead to substantial cost savings in product development activities, it can be better for the creator to launch the campaign for a basic version of a product and improve it during the campaign in response to customer feedback, even though this may decrease the chances of the campaign being successful.

Related Literature. As a phenomenon that has emerged quickly, crowdfunding has caught the attention of entrepreneurs, managers, and business scholars. Accordingly, there is a relatively new but growing literature on crowdfunding. We first discuss theoretical and empirical studies of crowdfunding and then summarize our contributions to this literature.

In the crowdfunding literature, $\mathrm{Hu}$ et al. (2015) have pioneered theoretical studies of rewardbased, all-or-nothing crowdfunding by analyzing whether the creator should offer a single reward or multiple rewards. Follow-up studies (e.g., Du et al. 2017, Chakraborty and Swinney 2019, 2021, Burtch et al. 2020, Li et al. 2020) analyze the creator's other design decisions, including the funding goal, the pledge price, limited rewards, and the timing of referrals and contingent stimulus policies (e.g., limited time offer). There are also theoretical studies that analyze how crowdfunding platforms can be designed to prevent misconduct (Strausz 2017, Belavina et al. 2020). ${ }^{4}$ Empirical studies focus mainly on factors that influence customers' pledging decisions and campaign success such as altruism, geographic proximity to creators, and creators' pre-campaign information sharing (e.g., Burtch et al. 2013, Mollick 2014, Agrawal et al. 2015, Lin and Viswanathan 2016, Kuppuswamy and Bayus 2017, Wei et al. 2020). Other empirical papers study broader aspects of crowdfunding such as the similarity between the evaluations of crowdfunding customers and those of experts (Mollick and Nanda 2016), the impact of crowdfunding on a creator's ability to reach venture capital investors (Sorenson et al. 2016), and differences between the pledge price and the

${ }^{4}$ There are other theoretical studies that ask broader questions about crowdfunding such as when to use different
forms of crowdfunding (e.g., Belleflamme et al. 2014, Bi et al. 2019) or how crowdfunding interacts with traditional
financing sources (e.g., Roma et al. 2018, Babich et al. 2021). Recently, Chemla and Tinn (2020) analyze the value of
crowdfunding as a tool to test the potential market. For a detailed review, we refer the reader to Chen et al. (2020). 
post-campaign retail price (Blaseg et al. 2020). Recently, Cornelius and Gokpinar (2020) show that crowdfunding campaigns are more likely to be successful with greater customer involvement. For a detailed review of this literature, we refer the reader to Allon and Babich (2020) and Chen et al. (2020).

While existing research has significantly improved our understanding of crowdfunding as a new financing (e.g., $\mathrm{Hu}$ et al. 2015, Belavina et al. 2020) and customer interaction mechanism (e.g., Mollick 2016, Cornelius and Gokpinar 2020), the product development decisions made by creators in crowdfunding have not received attention in the literature either theoretically or empirically. Our paper fills this gap by providing a nuanced understanding of crowdfunding as a product development mechanism. Specifically, inspired by practice and theoretical models in the crowdfunding literature, we first construct a theoretical model that includes the creator's decision on product improvement during the campaign. This model helps us build a theory about the impact of the initial enhancement level of a product on the likelihood of product improvement and campaign success. We then test this theory empirically with a unique large-scale data set. Our theory helps us generate practically grounded insights into whether the creator should improve a product as much as possible before the campaign. To our knowledge, our study is the first in the crowdfunding literature to combine theoretical and empirical analyses. Thus, one of its key strengths is that our theoretical and empirical analyses inform each other. Specifically, our theory helps us generate testable hypotheses for our empirical study, and our empirical results hint at the presence of behavioral effects and help us improve our theoretical model.

Our work is also related to the NPD literature that studies when to launch a product by considering different trade-offs. ${ }^{5}$ Specifically, assuming that a more enhanced product always increases the customer's utility, the majority of studies in this literature (e.g., Cohen et al. 1996, Özer and Uncu 2013, Gao et al. 2021) investigate how much to delay the launch to enhance the product by considering the risk of losing the first-mover advantage. Recently, Bhaskaran et al. (2020) consider a different trade-off: Launching a basic and immediately available version of a product brings earlier revenues (as opposed to delaying the launch to develop a more enhanced version), yet this may negatively affect the perception of future versions of the product. Different than the setting of these papers, we analyze a setting where launching a crowdfunding campaign for a basic version of the product neither brings any early revenue nor establishes any first-mover advantage. Therefore, we

${ }^{5}$ Our study is also related to the broader NPD literature (e.g., Thomke and Bell 2001, Loch et al. 2001, Erat and Kavadias 2008, Sommer et al. 2009) that has mainly focused on operational decisions related to experimentation and testing (e.g., whether to test sequentially or in parallel) mostly to resolve technical uncertainty before product launch. This literature suggests that cost of making changes and redesign increases over time in a product development process. We build our theoretical model based on this result, and study an innovative setting where product development continues based on customer feedback after product launch (i.e., launch of a crowdfunding campaign). 
identify a unique trade-off for product enhancement before launch that is relevant in crowdfunding settings and contribute to this literature on several fronts. First, we empirically show that enhancing the product too much before a crowdfunding campaign may reduce the likelihood of campaign success, which implies that the customer's utility does not always increase with the initial enhancement level of the product. Thus, the common assumption in product launch literature does not seem to hold in crowdfunding settings. Second, we consider a setting, where customers receive the final version of the product even though they pledge before the creator improves the product during the campaign. This unique feature of crowdfunding eliminates the risk of losing future value unlike settings where customers stick with the product they purchased even though the product is later improved. Despite this advantage, there are additional challenges for the creator because the creator receives pledges only when the campaign is successful, and improvements hinge on customers' voluntary feedback. Therefore, launching a more enhanced product may solicit more feedback and increase the chances of campaign success in crowdfunding, which may not be concerns in settings analyzed in the NPD literature. In sum, our study expands the NPD literature on product launch decisions by focusing on crowdfunding, a novel product development and financing setting.

The remainder of the paper is organized as follows. In $\S 2$, we discuss our theoretical model and its predictions; in $\S 3$, we discuss our empirical models and their results; in $\S 4$, we revise our theoretical model based on empirical results; in $\S 5$, we analyze the optimal initial enhancement level; and in $\S 6$, we discuss the results and limitations of our study.

\section{Theoretical Model and Analysis}

We consider a reward-based crowdfunding campaign where a creator elicits funds from customers ("she") to finance the launch of a physical product, ${ }^{6}$ and each customer pledges to receive the product as a reward. We focus on an all-or-nothing setting where the creator sets a funding goal, and if the total amount pledged exceeds the funding goal by the end of the campaign, the campaign is successful. In this case, the creator collects money pledged and delivers products to those who have pledged. When the total amount pledged does not meet the funding goal, the campaign fails, and hence the creator does not receive any funds or deliver any products and customers are refunded (e.g., Hu et al. 2015, Belavina et al. 2020).

Because crowdfunding is a nascent research area and our aim is to use our theoretical results to develop testable hypotheses, we develop a parsimonious model. Specifically, we build on the model of $\mathrm{Hu}$ et al. (2015) by incorporating the creator's product improvement decision and construct a four-stage game-theoretical model that involves one creator and two customers, as illustrated in

${ }^{6}$ Note that we focus on a campaign for a physical product such as camera equipment because a campaign for a non-physical product such as software may require a different model. 


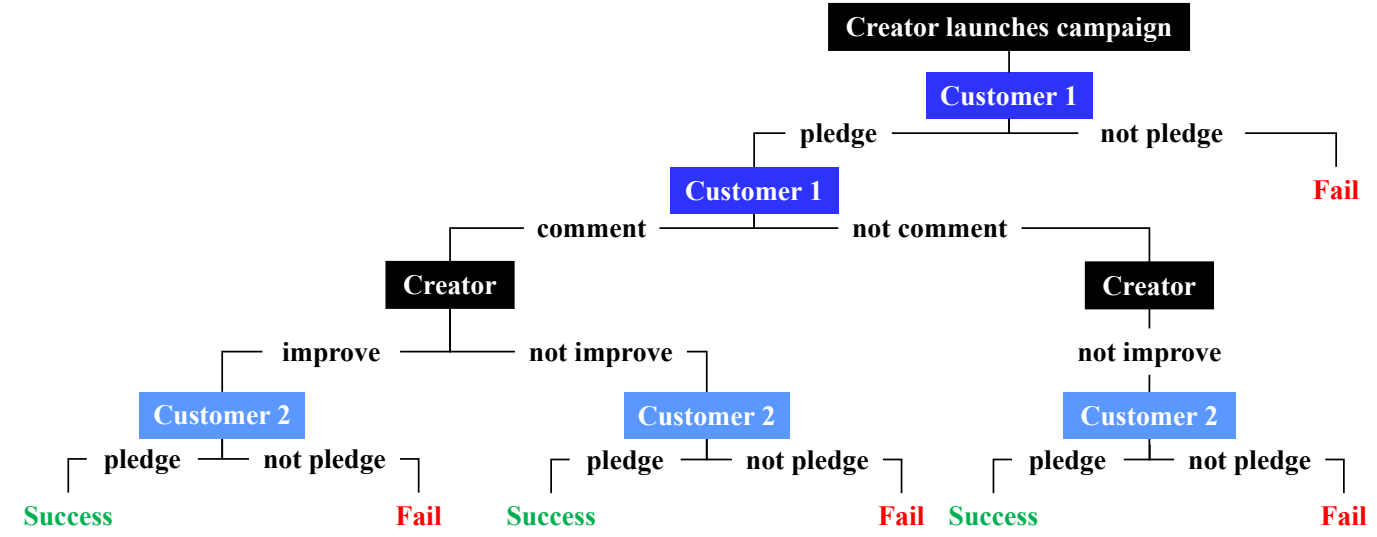

Figure 2 The sequence of decisions and events in a crowdfunding campaign where the product may potentially be improved during the campaign.

Figure 2. Table 1 summarizes the main assumptions in our model. We will describe our model according to the sequence of events.

Stage 0: The creator launches a crowdfunding campaign. The creator specifies a funding goal $G(>0)$ and an initial enhancement level $q_{i}(>0)$, which represents how enhanced the product is. For example, as we discuss in $\S 1$, HAIZE with wristband (i.e., a navigation device with more features) is a more enhanced version of the initially introduced navigation device. We assume that the creator incurs an investment cost of $C_{i} \cdot q_{i}$, where $C_{i} \geq 0$, to launch a campaign for a product whose initial enhancement level is $q_{i}$ (e.g., Chakraborty and Swinney 2021). Although the creator can also incur some investment cost when improving the product during the campaign, we normalize this cost to zero for ease of illustration. (Note that our results are qualitatively similar when we incorporate this cost into our model.) Therefore, the initial investment cost $C_{i}$ corresponds to the (opportunity) cost of enhancing the product before the campaign (e.g., the cost of market research, concept generation, design rework, or engineering changes) rather than involving customers in an earlier stage of product development. The creator sets the pledge price $p=G / 2$ so that the campaign is successful if and only if both customers pledge (Hu et al. 2015). ${ }^{7}$ To study our first two research questions (Q1) and (Q2) analytically and empirically, we consider the case when $q_{i}$ is exogenously given, so the initial investment $\operatorname{cost} C_{i} \cdot q_{i}$ is sunk. However, when we examine our third research question $(\mathrm{Q} 3), q_{i}$ is endogenously determined.

Stage 1: Customer 1's pledging decision. Customer 1 with valuation $v_{1}$ arrives at the campaign. For $j=\{1,2\}$, valuation $v_{j}$ measures customer $j$ 's marginal willingness to pay for the

${ }^{7}$ As a supplementary analysis, we also consider a model where two customers (instead of just customer 2) arrive after customer 1 yet the funding goal $G$ is still $2 p$. In this case, it is still possible that the campaign is successful if two out of three customers pledge, so no single customer is pivotal in whether the campaign will be successful. Our supplementary analysis of this case yields qualitatively similar results to our main results. 
Table 1 Summary of the main assumptions in the theoretical model.

\section{Assumptions}

References

Two customers arrive at the campaign sequentially, the funding goal $G=2 p$, and the per-unit production cost is $c q_{f}^{2}$, where $c>1$.

$v_{j}$ 's are i.i.d. with Uniform $(0,1)$.

Customers are fully refunded if the campaign fails.
Hu et al. (2015)

Krishnan and Ramachandran (2011), Belleflamme et al. (2014)

Hu et al. (2015), Chakraborty and Swinney (2021)

enhancement level of the product, and $v_{j}$ 's are independent across customers and drawn from a Uniform distribution with parameters 0 and 1 (e.g., Krishnan and Ramachandran 2011, Belleflamme et al. 2014). ${ }^{8}$ Once arrived at the campaign, customer 1 not only observes the pledge price $p$ and the initial enhancement level $q_{i}$ of the product from its detailed description but also anticipates the final enhancement level $q_{f}$ of the product. Thus, to decide whether to pledge or not, customer 1 compares her effective valuation $v_{1} \cdot q_{f}$ of the product and the pledge price $p$ (e.g., Belleflamme et al. 2014). If customer 1 does not pledge, the campaign fails, and both customers receive a reservation value of 0 . If customer 1 pledges, the next stage commences.

Stage 2: Customer 1's commenting decision. Customer 1 decides whether to make a comment to entice the creator to improve the product during the campaign, which can enhance the product by $q_{u}(>0)$. For instance, $q_{u}$ may represent the degree of improvement achieved by adding a wristband to the HAIZE navigation device, as discussed in $\S 1 .{ }^{9}$ If customer 1 does not make any comment, then the final enhancement level of the product is $q_{f}=q_{i}$.

Stage 3: The creator's product improvement decision. If customer 1 makes a comment with a enhancement level of $q_{u}$, then the creator decides whether to improve the product further or not. If the creator improves the product, then the final enhancement level of the product is $q_{f}=q_{i}+q_{u}$ (e.g., Krishnan and Ramachandran 2011); otherwise, $q_{f}=q_{i}$.

Stage 4: Customer 2's pledging decision. Customer 2 with valuation $v_{2}$ arrives at the campaign. Upon observing the final enhancement level $q_{f}$ and the pledge price $p$, she decides whether to pledge or not. If customer 2 pledges along with customer 1, the campaign is successful, and the creator receives pledges and delivers products to customers by incurring a per-unit production cost of $c \cdot q_{f}^{2}$, where $c>0$ (e.g., materials and labor; Guo and Zhang 2012, Hu et al. 2015). If customer 2

\footnotetext{
${ }^{8}$ In the crowdfunding literature (e.g., Hu et al. 2015), it is common to assume such a distribution on valuations.

${ }^{9}$ For ease of illustration, we assume that the customer's cost of commenting is negligible compared to the utility she can obtain from a potential improvement in the product. In Online Appendix EC.1, we extend our analysis to the case where the customer incurs some non-negligible cost when she makes a comment.
} 
does not pledge, then the campaign fails. (Our results are qualitatively similar when the per-unit production cost is $c \cdot q_{f}$.)

\subsection{Analysis of Sub-game Perfect Equilibrium}

For any given pledge price $p$ and initial enhancement level $q_{i}$, we determine the sub-game perfect equilibrium via backward induction. First, in Stage 4 , customer 2 with valuation $v_{2} \sim \operatorname{Uniform}(0,1)$ pledges if and only if her expected utility $U_{2}=v_{2} q_{f}-p \geq 0$. If the creator improved the product in Stage 3, the final enhancement level $q_{f}=q_{i}+q_{u}$, and hence customer 2 pledges with probability $\frac{q_{i}+q_{u}-p}{q_{i}+q_{u}}$. Otherwise, the final enhancement level $q_{f}=q_{i}$, and hence customer 2 pledges with probability $\frac{q_{i}-p}{q_{i}}$. We assume that $q_{i}>p$ to avoid trivial cases where even a customer with maximum valuation does not pledge when there is no improvement.

In Stage 3, if customer 1 pledged and made a comment in Stages 1 and 2, the creator decides whether to improve the product during the campaign by comparing the creator's expected profit $\Pi^{I}$ with improvement and expected profit $\Pi^{N I}$ with no improvement. By taking customer 2's pledging probability $\frac{q_{i}+q_{u}-p}{q_{i}}$ and the per-unit production cost $c\left(q_{i}+q_{u}\right)^{2}$ into consideration, the creator's expected profit with an improvement is $\Pi^{I}=\left(\frac{q_{i}+q_{u}-p}{q_{i}+q_{u}}\right)\left(2 p-2 c\left(q_{i}+q_{u}\right)^{2}\right)-C_{i} q_{i} \cdot{ }^{10}$ Similarly, the creator's expected profit without improvement is $\Pi^{N I}=\left(\frac{q_{i}-p}{q_{i}}\right)\left(2 p-2 c q_{i}^{2}\right)-C_{i} q_{i}$. Thus, the creator improves the product during the campaign if and only if $\Pi^{I} \geq \Pi^{N I}$, i.e.,

$$
\frac{p^{2}}{q_{i}\left(q_{i}+q_{u}\right)}-c\left(2 q_{i}+q_{u}-p\right) \geq 0
$$

In Stage 2, if customer 1 pledged in Stage 1, she decides whether to make a comment or not. First, suppose that condition (1) is violated. Then, even if customer 1 makes a comment, she anticipates that the creator will not improve the product in Stage 3 and customer 2 will pledge in Stage 4 with probability $\frac{q_{i}-p}{q_{i}}$. Thus, in this case, customer 1's expected utility is $U_{1}^{C}=\left(\frac{q_{i}-p}{q_{i}}\right)\left(v_{1} q_{i}-p\right)$. Similarly, if customer 1 does not make a comment, she anticipates that customer 2 will pledge in Stage 4 with probability $\frac{q_{i}-p}{q_{i}}$, and hence customer 1's expected utility is $U_{1}^{N C}=U_{1}^{C}$. Since $U_{1}^{N C}=U_{1}^{C}$, the cases where customer 1 makes a comment and does not make a comment are both in equilibria.

Now, suppose that condition (1) holds. Then, if customer 1 makes a comment, she anticipates that the creator will improve the product in Stage 3 and customer 2 will pledge in Stage 4 with probability $\frac{q_{i}+q_{u}-p}{q_{i}+q_{u}}$. Thus, in this case, customer 1's expected utility is $U_{1}^{C}=\left(\frac{q_{i}+q_{u}-p}{q_{i}+q_{u}}\right)\left(v_{1}\left(q_{i}+q_{u}\right)-p\right)$. However, if customer 1 does not make a comment, she anticipates that customer 2 will pledge in

${ }^{10}$ Although we normalize the unit investment cost $C_{u}$ of improving the product to zero, our results are qualitatively similar when $C_{u}>0$; i.e., $\Pi^{I}=\left(\frac{q_{i}+q_{u}-p}{q_{i}+q_{u}}\right)\left(2 p-2 c\left(q_{i}+q_{u}\right)^{2}\right)-C_{i} q_{i}-C_{u} q_{u}$. 
Stage 4 with probability $\frac{q_{i}-p}{q_{i}}$, and hence customer 1's expected utility is $U_{1}^{N C}=\left(\frac{q_{i}-p}{q_{i}}\right)\left(v_{1} q_{i}-p\right)$. Therefore, customer 1 makes a comment in Stage 2 if and only if $U_{1}^{C} \geq U_{1}^{N C}$, i.e., $v_{1} \geq \frac{p^{2}}{q_{i}\left(q_{i}+q_{u}\right)}$.

Finally, in Stage 1, customer 1's pledging decision depends on whether she anticipates an improvement in the product or not. First, suppose that condition (1) holds so that customer 1 anticipates an improvement and makes a comment when $v_{1} \geq \frac{p^{2}}{q_{i}\left(q_{i}+q_{u}\right)}$. Then, customer 1 decides whether to pledge or not by comparing her expected utility $U_{1}^{P}$ when she pledges, where $U_{1}^{P}=U_{1}^{C}=$ $\left(\frac{q_{i}+q_{u}-p}{q_{i}+q_{u}}\right)\left(v_{1}\left(q_{i}+q_{u}\right)-p\right)$, and her expected utility $U_{1}^{N P}$ when she does not pledge, where $U_{1}^{N P}=0$. Thus, customer 1 pledges if and only if $U_{1}^{P} \geq U_{1}^{N P}$, i.e., $v_{1} \geq \frac{p}{q_{i}+q_{u}}$. Therefore, in a setting where customer 1 anticipates an improvement, she pledges and makes a comment if

$$
v_{1} \geq \max \left\{\frac{p^{2}}{q_{i}\left(q_{i}+q_{u}\right)}, \frac{p}{q_{i}+q_{u}}\right\}=\frac{p}{q_{i}+q_{u}} .
$$

This means that if condition (1) holds, customer 1 makes a comment whenever she pledges. Second, suppose that condition (1) is violated. Then, regardless of customer 1's commenting decision in Stage 3, customer 2 pledges in Stage 4 with probability $\frac{q_{i}-p}{q_{i}}$. In this case, customer 1's expected utility when she pledges is $U_{1}^{P}=\left(\frac{q_{i}-p}{q_{i}}\right)\left(v_{1} q_{i}-p\right)$, and her expected utility when she does not pledge is $U_{1}^{N P}=0$. Thus, customer 1 pledges if and only if $v_{1} \geq \frac{p}{q_{i}}$.

By using the creator's and customers' rational strategies explained above, we next characterize the equilibrium outcomes. We aim to understand how the initial enhancement level affects whether the product is improved during a campaign or not. Thus, we calculate the ex-ante probability that there is an improvement in the product during the campaign, and we denote this probability by $\mathbb{P}($ improve $)$. Also, let $\mathbb{P}$ (success $)$ be the ex-ante probability that the campaign is successful. The following lemma characterizes these equilibrium outcomes. We present all proofs in Appendix A.

Lemma 1. If $\frac{p^{2}}{q_{i}\left(q_{i}+q_{u}\right)}-c\left(2 q_{i}+q_{u}-p\right) \geq 0$, then $\mathbb{P}($ improve $)=\frac{q_{i}+q_{u}-p}{q_{i}+q_{u}}$ and $\mathbb{P}($ success $)=$ $\left(\frac{q_{i}+q_{u}-p}{q_{i}+q_{u}}\right)^{2}$; otherwise, $\mathbb{P}($ improve $)=0$ and $\mathbb{P}($ success $)=\left(\frac{q_{i}-p}{q_{i}}\right)^{2}$.

Lemma 1 first characterizes the case where condition (1) holds so that the creator is willing to improve the product during the campaign and customer 1 makes a comment whenever she pledges. In this case, customer 1 pledges and makes a comment with probability $\frac{q_{i}+q_{u}-p}{q_{i}+q_{u}}$, and hence $\mathbb{P}($ improve $)=\frac{q_{i}+q_{u}-p}{q_{i}+q_{u}}$. Also, customer 2 pledges with probability $\frac{q_{i}+q_{u}-p}{q_{i}+q_{u}}$, and hence $\mathbb{P}($ success $)=$ $\left(\frac{q_{i}+q_{u}-p}{q_{i}+q_{u}}\right)^{2}$. Lemma 1 also characterizes the case where condition (1) is violated. In this case, regardless of customer 1 making a comment or not, $\mathbb{P}($ improve $)=0$ and $\mathbb{P}($ success $)=\left(\frac{q_{i}-p}{q_{i}}\right)^{2}$. Note that, ceteris paribus, $\mathbb{P}$ (success) is greater when the creator improves the product during the campaign, which is consistent with the empirical finding of Cornelius and Gokpinar (2020). 


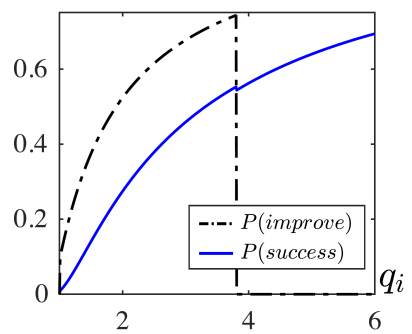

Figure 3 The impact of the initial enhancement level $q_{i}$ on $\mathbb{P}($ improve $)$ and $\mathbb{P}($ success $)$. The setting: $p=1$, $c=0.01$, and $q_{u}=0.1$.

\subsection{Probability of Product Improvement}

Using Lemma 1, we next answer our first research question (Q1). The following proposition characterizes the impact of the initial enhancement level $q_{i}$ on $\mathbb{P}$ (improve).

Proposition 1. There exists a threshold $\overline{q_{i}}(\geq 0)$ such that when the initial enhancement level $q_{i} \leq \overline{q_{i}}, \mathbb{P}($ improve $)$ increases with $q_{i}$; and when $q_{i}>\overline{q_{i}}, \mathbb{P}($ improve $)=0$.

One might expect that the higher the initial enhancement level $q_{i}$, the less likely the product is to be improved during the campaign. However, Proposition 1 shows that the probability of product improvement during the campaign increases with the initial enhancement level $q_{i}$ up to a threshold $\overline{q_{i}}$ but above this threshold, the creator does not improve the product during the campaign, as illustrated in Figure 3. The intuition is as follows. $\mathbb{P}$ (improve) depends on the decisions of both the creator and customer 1. First, consider the creator's improvement decision. When the creator improves the product during the campaign, the product becomes more enhanced, and hence each customer is more likely to pledge, yet the creator expects to incur a higher production cost (i.e., $c\left(q_{i}+q_{u}\right)^{2}$ instead of $\left.c q_{i}^{2}\right)$. When the initial enhancement level $q_{i}$ is higher, improving the product leads to a smaller increase in the customer's likelihood of pledging and a larger increase in the cost of production. Because of these opposing forces, the creator improves the product during the campaign only when $q_{i}$ is below a certain threshold (i.e., $\left.q_{i} \leq \overline{q_{i}}\right){ }^{11}$

Next, consider the decisions of customer 1. As $q_{i}$ increases, customer 1's expected utility increases, and customer 1 is thus more likely to pledge and make a comment, which increases $\mathbb{P}($ improve $)$. However, this is possible only when the creator improves the product further (i.e., $q_{i} \leq \overline{q_{i}}$ ). Thus, $\mathbb{P}($ improve $)$ increases with $q_{i} \leq \overline{q_{i}}$, but $\mathbb{P}($ improve $)=0$ when $q_{i}>\overline{q_{i}}$.

Based on Proposition 1, we establish the following hypothesis (hereafter H1).

Hypothesis 1. As the initial enhancement level of a product increases, the likelihood that the product will be improved during the campaign first increases and then decreases.

${ }^{11}$ Even when the marginal cost of production is constant (i.e., cost of production is $c \cdot q_{f}$ ), this result continues to hold because as $q_{i}$ increases, improving the product leads to a smaller increase in the customer's likelihood of pledging. 


\subsection{Probability of Campaign Success}

We next use Lemma 1 to answer our second research question (Q2). The following proposition characterizes the impact of the initial enhancement level $q_{i}$ on $\mathbb{P}$ (success).

Proposition 2. (i) When $\frac{p^{2}}{q_{i}\left(q_{i}+q_{u}\right)}-c\left(2 q_{i}+q_{u}-p\right) \neq 0, \mathbb{P}($ success $)$ is increasing in $q_{i}$. (ii) Also, there exists a threshold $\underline{q_{i}}(>0)$ such that for $q_{i}>\underline{q_{i}}, \mathbb{P}($ success $)$ is concave in $q_{i}$.

Proposition 2 shows that, regardless of whether condition (1) holds with strict inequality or it is violated (i.e., whether the creator is willing to improve the product during the campaign or not), the probability of campaign success increases with the initial enhancement level $q_{i}$, but at a decreasing rate when $q_{i}$ is above a threshold; see Figure $3(\mathrm{a}) .{ }^{12}$ The intuition behind Proposition 2 (i) is that as the initial enhancement level $q_{i}$ increases, each customer's expected utility increases, and the customer is thus more likely to pledge. Thus, $\mathbb{P}($ success $)$ increases with $q_{i}$. Proposition 2(ii) stems from two opposing effects. First, as $q_{i}$ increases, the marginal benefit of increasing $q_{i}$ on each customer's probability of pledging decreases. Second, there is also an indirect effect of one customer's pledging on the other one's decision, and the marginal benefit of increasing $q_{i}$ on this indirect effect increases with $q_{i}$. When $q_{i}$ is above a certain threshold (i.e., $q_{i}>\underline{q_{i}}$ ), the former effect is more dominant than the latter, so the marginal benefit of increasing $q_{i}$ on the probability of campaign success decreases.

Based on Proposition 2, we establish the following hypothesis (hereafter H2).

Hypothesis 2. As the initial enhancement level of a product increases, the likelihood of campaign success increases, but at a decreasing rate when the initial enhancement level is high.

\section{Empirical Models and Analysis}

We test H1 and H2 by using a unique data set collected from Kickstarter, a crowdfunding platform that enables creators to launch reward-based, all-or-nothing campaigns. To launch a campaign on Kickstarter, each creator first prepares a campaign page that includes a textual description of the product along with supporting materials such as pictures. On the campaign page, the creator also specifies a funding goal and the pledge price required to receive the product as a reward. Once the campaign has been launched, a customer arriving on the campaign page reads the product description to decide whether or not to pledge. As we discuss in $\S 1$, if a customer pledges, she can make a comment on the campaign page to induce the creator to improve the product further (customers cannot make comments before pledging; see Kickstarter 2021h); and if the creator

${ }^{12}$ Note that when $\frac{p^{2}}{q_{i}\left(q_{i}+q_{u}\right)}-c\left(2 q_{i}+q_{u}-p\right)=0$, the creator does not improve the product during the campaign as $q_{i}$ increases, and hence $\mathbb{P}($ success $)$ decreases from $\left(\frac{q_{i}+q_{u}-p}{q_{i}+q_{u}}\right)^{2}$ to $\left(\frac{q_{i}-p}{q_{i}}\right)^{2}$. 
improves the product, the creator revises the product description accordingly. After the campaign ends, customers cannot pledge or the creator cannot revise the product description. As we discuss in $\S 2$, if the total amount pledged at the end exceeds the funding goal, the campaign is successful; otherwise, the campaign fails and customers are refunded. In the remainder of this section, we describe the sample, variables, empirical models, and empirical results.

\subsection{Sample}

Consistent with our theoretical model, we focus on 21,768 campaigns for physical products in the Technology and Design categories launched on Kickstarter between July 2013 and February 2016 . $^{13}$ The sample contains 6,488 successful campaigns, 12,111 failed campaigns, and 3,169 cancelled campaigns. ${ }^{14}$ We exclude 388 campaigns that are not suitable for textual analysis (e.g., non-English campaigns, see $\S 3.2)$, so the final sample contains 21,380 campaigns.

\subsection{Dependent, Explanatory, and Control Variables}

Dependent Variables: Product Improvement and Campaign Success. To test H1, we need a variable that measures whether a creator improves the product during a campaign or not. Hence, we generate a binary variable, product improvement $I_{k}$, for each campaign $k$ that represents whether the final enhancement level $q_{f k}$ of the product in campaign $k$ is higher than its initial enhancement level $q_{i k}$. (We explain how we construct $q_{i k}$ and $q_{f k}$ when we discuss level of enhancement below.) Specifically, $I_{k}=1$ if $q_{f k}>q_{i k}$; otherwise, $I_{k}=0$. In our sample, $26 \%$ of all products and $43 \%$ of products in successful campaigns were improved during their campaigns.

To test H2, we create a binary variable, campaign success $S_{k}$, for each campaign $k$ that represents whether the total amount pledged $P_{k}$ at the end of the campaign is greater than or equal to the funding goal $G_{k}$ (e.g., Mollick 2014, Wei et al. 2020). Specifically, $S_{k}=1$ if $P_{k} \geq G_{k}$; otherwise, $S_{k}=0$. This measure is important for creators to evaluate their success, and it is also consistent with how Kickstarter evaluates campaigns to analyze the performance of the platform (Kickstarter $2021 \mathrm{~g}$ ). In our sample, $35 \%$ of campaigns were successful (excluding cancelled campaigns).

Level of Enhancement. The NPD literature identifies that product developers typically design their products by first outlining the core features and then adding more features (e.g., Ulrich and Eppinger 2016). Products that are more enhanced therefore tend to have more features (e.g.,

\footnotetext{
${ }^{13}$ These campaigns constitute the majority of the Technology and Design campaigns, and include product subcategories such as camera equipment, hardware, and product design, but not software, web, and graphic design. Our additional analysis shows that the empirical results reported in $\S 3.4$ continue to hold when we include campaigns for non-physical products.

${ }^{14}$ Campaigns can be cancelled due to intellectual property disputes or at the discretion of creators (Kickstarter 2021b). Although we exclude cancelled campaigns in our main empirical analyses, our empirical results continue to hold when we treat them as failed campaigns (see §3.4).
} 
Althuizen and Chen 2021). Utilizing this relationship, we measure the initial and final enhancement levels of products through the number of features by leveraging products' textual descriptions at the beginning and end of their campaigns.

Following the prior literature (e.g., Tirunillai and Tellis 2014, Toubia et al. 2019), we use latent Dirichlet allocation (LDA; Blei et al. 2003) to create a proxy for the number of features by extracting topics and their weights in each description. Our approach is as follows. We train the LDA model on 42,564 initial and final descriptions of 21,380 campaigns in our sample. (We discuss the details of the LDA model in Appendix B.1.) For each description, we multiply the description's topic weights by the description length (in words) to get the number of words associated with a particular topic. In line with the prior literature (e.g., Blei et al. 2003, Griffiths and Steyvers 2004), we consider a topic to be present in a description if it is associated with at least ten words. (Our empirical results continue to hold when we use different thresholds; see §3.4.) Then, in each campaign $k$, we measure the product's initial enhancement level $q_{i k}$ as the number of topics in its initial description and the product's final enhancement level $q_{f k}$ as the number of topics in its final description. For example, the initial enhancement level of the HAIZE navigation device discussed in $\S 1$ is calculated as 14, whereas its final enhancement level is calculated as 19, consistent with the fact that it was improved during its campaign. (See Figure B1 in Appendix B.1 for the initial and final descriptions of this product.) In our sample, the average initial enhancement level is 9.02 and the average final enhancement level is 9.59 . As we need both $q_{i k}$ and $q_{f k}$ to calculate $I_{k}$, we exclude 196 campaigns which only have either an initial or a final description after pre-processing (see Appendix B.1).

Control Variables. In our empirical models, we include several controls for campaign and creator characteristics. Specifically, we control for the category of each campaign (i.e., technology or design; we set design as the base category in empirical models) because the initial enhancement level of a product can differ across categories. Also, we control for each campaign's funding goal (natural logarithm of goal in US dollars) and duration (in days) (e.g., Mollick 2014, Blaseg et al. 2020). These variables enable us to control for the scale of a project because, for example, we can expect the goal to be higher and/or the duration of the campaign to be longer for a larger scale project. Additionally, we control for the median pledge price (in US dollars) of each campaign and the delivery time (the number of months between the last delivery date and the end of the campaign), which are also linked to the scale of the project. ${ }^{15}$

In our analysis, we derive the enhancement level of products from their textual descriptions. Because these descriptions can also include videos and pictures as well as a section in which creators

${ }^{15}$ Our additional analysis indicates that the median pledge price is a good proxy for the pledge price of the product in each campaign, but our empirical results hold when we control for the mean pledge price in each campaign. 
discuss various risks associated with their campaigns, we control for the number of videos, the number of pictures, and risk-section length (in words) (e.g., Blaseg et al. 2020).

We include additional control variables to take into account various creator-related factors that may affect the likelihood of product improvement or campaign success. First, we control for creator experience in terms of the number of previous campaigns launched by a creator. Second, we control for whether the creator is an individual or not, which we define as follows. If the majority of personal pronouns in the product description are singular and the creator is not an organization with legal name (e.g., Ltd, Inc), the creator is an individual; if not, the creator is not an individual.

Finally, we control for the average level of competition during each campaign as follows. For each category and each day, we calculate the number of concurrent campaigns and the number of new customers, ${ }^{16}$ and we then divide these two variables to obtain "campaign-customer" ratio. Then, for each campaign, we control for the average campaign-customer ratio during the campaign.

\subsection{Model Specification}

Our empirical strategy relies on probit models and an instrumental variable (IV) approach to address potential endogeneity concerns.

Probit Models. Because our dependent variables, product improvement $I_{k}$ and campaign success $S_{k}$, are binary, we use probit models to test $\mathrm{H} 1$ and $\mathrm{H} 2$. Let $X_{k}$ be the vector of control variables for campaign $k$. First, to test the nonlinear (first increasing and then decreasing) relationship between initial enhancement level $q_{i k}$ on product improvement $I_{k}$ in H1, we include both $q_{i k}$ and $\left(q_{i k}\right)^{2}$, and obtain the following probit model (Probit Model 1):

$$
I_{k}=\beta_{0}+\beta_{1} q_{i k}+\beta_{2}\left(q_{i k}\right)^{2}+\beta_{X} X_{k}+v_{k}
$$

Next, to test the nonlinear (increasing with diminishing returns after some initial enhancement level) relationship between initial enhancement level $q_{i k}$ on campaign success $S_{k}$ in $\mathrm{H} 2$, we include both $q_{i k}$ and $\left(q_{i k}\right)^{2}$, and obtain the following probit model (Probit Model 2):

$$
S_{k}=\beta_{0}+\beta_{1} q_{i k}+\beta_{2}\left(q_{i k}\right)^{2}+\beta_{X} X_{k}+v_{k}
$$

Instrumental Variable. Although we control for campaign and creator characteristics, there may still be unobserved factors that can simultaneously affect initial enhancement level $q_{i k}$ in campaign $k$ and product improvement $I_{k}$ as well as campaign success $S_{k}$. To address this problem and any potential measurement errors, we use an exogenous shock to the level of product enhancement

${ }^{16}$ On December 19, 2013, the number of new customers is zero in both categories due to a server error, so we replace the number of new customers on this day with the average number of customers in each category. 


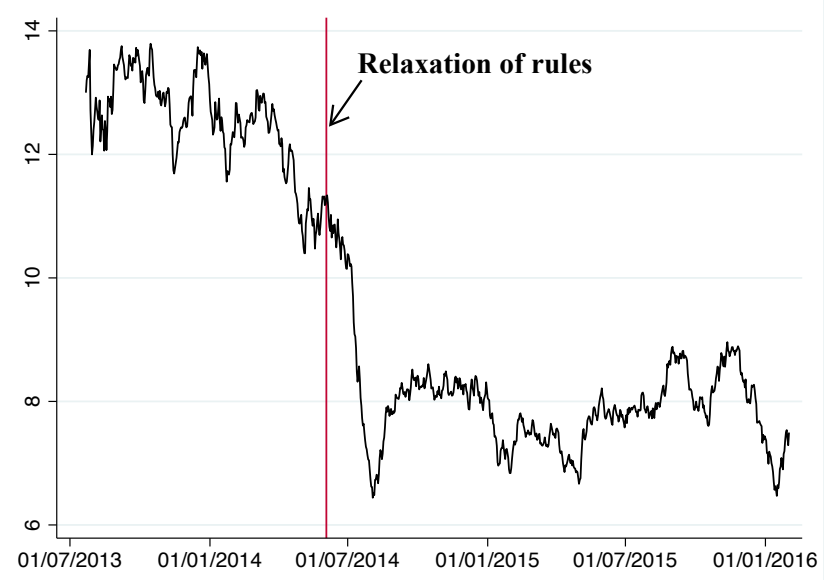

Figure 4 30-day moving average of products' initial enhancement levels by campaign start dates.

that is required before a Kickstarter campaign can be launched. Specifically, on June 3, 2014, Kickstarter introduced a new policy in which the campaign requirements were relaxed (Kickstarter 2021d). As Figure 4 illustrates, this exogenous shock leads to a substantial decrease in the average initial enhancement level of products. Using this exogenous shock as an instrument allows us to isolate the impact of the initial enhancement level on our outcome variables. ${ }^{17}$

To use this instrument in our IV models, we create a binary variable, before relaxation of rules $B_{k}$, where $B_{k}=1$ if campaign $k$ is launched before June 3, 2014, and $B_{k}=0$ otherwise. Since we focus on campaigns launched between July 2013 and February 2016, we have comparable time periods before and after the instrument. This also enables us to avoid a confounding event on February 2, 2016, when Kickstarter started selecting curated campaigns (Kickstarter 2021c). Note that the $F$-statistic in the regression of the initial enhancement level on $B_{k}$ is 900.10 , which indicates that our IV satisfies the relevance condition.

IV Models. In our empirical analysis, we aim to analyze the nonlinear relationship between an endogenous explanatory variable and a binary dependent variable, so using a standard two-stage least squares (2SLS) approach would be problematic. Thus, we implement the instrumental variable using a control function approach (Wooldridge 2010, 2015), a two-step approach that allows us to condition out the variation in unobserved variables that depends on the endogenous variable, and hence the remaining variation in the endogenous variable is independent of the error (Petrin and Train 2010).

${ }^{17}$ A concern may be that the relaxation of rules simultaneously leads to an increase in the number of campaigns and thereby reduces each campaign's likelihood of success. This would violate the exclusion restriction, by which an instrument cannot affect an outcome variable directly but only through the instrumented explanatory variable. To satisfy the exclusion restriction, we include the level of competition as an additional control variable. The instrument is then independent of campaign success, conditional on the explanatory variable and the level of competition. 
Table 2 Descriptive statistics of variables in the empirical models $(n=18,173)$.

\begin{tabular}{lcccc}
\hline Variables & Mean & Standard deviation & Minimum & Maximum \\
\hline Product improvement & 0.26 & 0.44 & 0 & 1 \\
Campaign success & 0.35 & 0.48 & 0 & 1 \\
Initial enhancement level & 9.02 & 8.11 & 0 & 48 \\
Goal $(\mathrm{ln})$ & 9.48 & 1.64 & -0.28 & 18.52 \\
Duration & 34.63 & 10.5 & 0 & 61 \\
Pledge price & 174.95 & 535.09 & 0 & 10000 \\
Delivery time & 4.27 & 5.03 & 0 & 70 \\
Videos & 0.26 & 0.83 & 0 & 119 \\
Pictures & 11.08 & 12.11 & 8 & 4981 \\
Risk-section length & 141.64 & 119.95 & 0 & 21 \\
Creator experience & 0.18 & 0.78 & 0 & 1 \\
Individual & 0.31 & 0.46 & 0.05 & 0.54 \\
Competition & 0.16 & 0.04 & 0 & 1 \\
Before relaxation of rules & 0.22 & 0.41 & 0 & \\
\hline
\end{tabular}

Note. The minimum value of the natural logarithm of the goal (in US dollars) is negative because the minimum value of the goal is one Canadian dollar. Our empirical results continue to hold when we exclude 324 campaigns where the goal (in US dollars) is smaller than the $1^{\text {st }}$ percentile $(\$ 168)$ or larger than the $99^{\text {th }}$ percentile $(\$ 500,000)$.

To test H1 with the IV model, we use the following procedure as explained in Wooldridge (2015) (for an example in the operations management literature, see Chan et al. 2020). In the first stage, we regress the initial enhancement level $q_{i k}$ on the instrumental variable $B_{k}$ and control variables in an ordinary least-squares model. We then use the predicted residuals $\hat{u}_{k}$ of the first-stage regression in the second-stage probit model whose dependent variable is product improvement $I_{k}$ (Wooldridge 2015). Because $\hat{u}_{k}$ is an estimate from the first stage, which adds extra variation in the second stage (Petrin and Train 2010), we also use a nonparametric bootstrap to obtain valid standard errors in the second stage (Wooldridge 2010, 2015). For H1, we obtain the IV model (IV Model 1) with the following first- and second-stage regressions:

$$
\begin{aligned}
q_{i k} & =\alpha_{0}+\alpha_{1} B_{k}+\alpha_{X} X_{k}+u_{k}, \text { and } \\
I_{k} & =\beta_{0}+\beta_{1} q_{i k}+\beta_{2}\left(q_{i k}\right)^{2}+\beta_{3} \hat{u}_{k}+\beta_{4}\left(\hat{u}_{k}\right)^{2}+\beta_{X} X_{k}+v_{k} .
\end{aligned}
$$

To test the nonlinear relationship between $q_{i k}$ and $I_{k}$, we include both $\left(q_{i k}\right)^{2}$ and $\left(\hat{u}_{k}\right)^{2}$ in the second-stage regression (Wooldridge 2015, page 437). ${ }^{18}$ Similarly, to test H2, we obtain the IV model (IV Model 2) with the following first- and second-stage regressions:

$$
\begin{aligned}
& q_{i k}=\alpha_{0}+\alpha_{1} B_{k}+\alpha_{X} X_{k}+u_{k}, \text { and } \\
& S_{k}=\beta_{0}+\beta_{1} q_{i k}+\beta_{2}\left(q_{i k}\right)^{2}+\beta_{3} \hat{u}_{k}+\beta_{4}\left(\hat{u}_{k}\right)^{2}+\beta_{X} X_{k}+v_{k} .
\end{aligned}
$$

\footnotetext{
${ }^{18}$ Note that there is no forbidden regression problem in our model because we do not directly plug predicted values of $q_{i k}$ from the first stage in the nonlinear second-stage regression (cf. Angrist and Pischke 2009). Instead, we implement control function approach, which was developed as a solution to the forbidden regression problem (Wooldridge 2010, 2015, Petrin and Train 2010), and hence we use predicted residuals $\hat{u}_{k}$.
} 
Table 3 Correlation matrix for variables in the empirical models $(n=18,173)$.

\begin{tabular}{|c|c|c|c|c|c|c|c|c|c|c|c|c|c|}
\hline Variables & $(1)$ & (2) & (3) & (4) & $(5)$ & (6) & (7) & $(8)$ & (9) & $(10)$ & $(11)$ & $(12)$ & (13) \\
\hline (1) Product improvement & 1.00 & & & & & & & & & & & & \\
\hline (2) Campaign success & $0.28^{* * *}$ & 1.00 & & & & & & & & & & & \\
\hline (3) Initial enhancement level & $0.18^{* * *}$ & $0.21^{* * *}$ & 1.00 & & & & & & & & & & \\
\hline (4) Goal (ln) & $0.07^{* * *}$ & $-0.22 * * *$ & $0.25^{* * *}$ & 1.00 & & & & & & & & & \\
\hline (5) Duration & $0.04^{* * *}$ & $-0.05^{* * *}$ & $0.05^{* * *}$ & $0.22 * * *$ & 1.00 & & & & & & & & \\
\hline (6) Pledge price & 0.01 & $-0.04 * * *$ & $0.04^{* * *}$ & $0.18^{* * *}$ & $0.02^{* * *}$ & 1.00 & & & & & & & \\
\hline (7) Delivery time & $0.01 *$ & $-0.08 * * *$ & $0.05^{* * *}$ & $0.26^{* * *}$ & $0.10^{* * *}$ & $0.10^{* * *}$ & 1.00 & & & & & & \\
\hline (8) Videos & $0.05^{* * *}$ & $0.04 * * *$ & $0.18^{* * *}$ & $0.11^{* * *}$ & $0.04^{* * *}$ & 0.01 & $0.01 *$ & 1.00 & & & & & \\
\hline (9) Pictures & $0.19^{* * *}$ & $0.32 * * *$ & $0.53^{* * *}$ & $0.17^{* * *}$ & $0.08^{* * *}$ & 0.00 & 0.00 & $0.18^{* * *}$ & 1.00 & & & & \\
\hline (10) Risk-section length & $0.09 * * *$ & $0.06 * * *$ & $0.36^{* * *}$ & $0.20^{* * *}$ & $0.03 * * *$ & $0.03 * * *$ & $0.07^{* * *}$ & $0.09 * * *$ & $0.21^{* * *}$ & 1.00 & & & \\
\hline (11) Creator experience & $0.01 *$ & $0.17^{* * *}$ & -0.01 & $-0.18^{* * *}$ & $-0.03 * * *$ & $-0.03^{* * *}$ & $-0.06^{* * *}$ & 0.00 & $0.04^{* * *}$ & $-0.03 * * *$ & 1.00 & & \\
\hline (12) Individual & $-0.09 * * *$ & $-0.12 * * *$ & $-0.14 * * *$ & $-0.18^{* * *}$ & $-0.06 * * *$ & $-0.02 * * *$ & 0.01 & $-0.06 * * *$ & $-0.21 * * *$ & $-0.08 * * *$ & 0.00 & 1.00 & \\
\hline (13) Competition & $-0.06^{* * *}$ & $-0.09^{* * *}$ & $-0.14 * * *$ & 0.01 & $0.06^{* * *}$ & $0.04^{* * *}$ & $0.05^{* * *}$ & $0.02 * * *$ & $-0.09 * * *$ & $-0.04 * * *$ & $0.02 * *$ & $0.01^{*}$ & 1.00 \\
\hline
\end{tabular}

\subsection{Results}

Tables 2 and 3 show the descriptive statistics and correlations (we exclude 3,011 cancelled campaigns). We report no issue of multicollinearity. All the results are presented in Table 4. The effects of control variables on our outcome variables in both models are as expected. For example, compared to teams, individual creators are less likely to improve their products and their campaigns are less likely to be successful.

Results of Probit Models. In Probit Model 1, the coefficient of initial enhancement level $q_{i k}$ is positive and significant $\left(\gamma_{1}=0.072, p<0.01\right)$ and the coefficient of $\left(q_{i k}\right)^{2}$ is negative and significant $\left(\gamma_{2}=-0.002, p<0.01\right)$. As Figure 5(a) illustrates, this result supports H1. In Probit Model 2, the coefficient of initial enhancement level $q_{i k}$ is positive and significant $\left(\gamma_{1}=0.088, p<0.01\right)$ and the coefficient of $\left(q_{i k}\right)^{2}$ is negative and significant $\left(\gamma_{2}=-0.002, p<0.01\right)$. As Figure $5(\mathrm{~b})$ illustrates, this result shows that as the initial enhancement level increases, the likelihood of campaign success first increases but then decreases. Hence, this result does not support H2.

Results of IV Models. We next discuss the results of the IV models (see Table 4). The second stage of IV Model 1 shows the results for H1. While the coefficient of initial enhancement level $q_{i k}$ is positive and significant $\left(\gamma_{1}=0.103, p<0.01\right)$, the coefficient of $\left(q_{i k}\right)^{2}$ is negative and significant $\left(\gamma_{2}=-0.002, p<0.01\right)$. We also calculate the turning point as $q_{i k}=23.12$ and its $95 \%$ confidence interval as $(19.46,27.33)$, and both the turning point and its confidence interval are within the data range (e.g., Haans et al. 2016, Tan and Netessine 2019). As Figure 5(c) illustrates, this result indicates that as the initial enhancement level increases, the likelihood of product improvement first increases and then decreases, supporting H1.

The second stage of IV Model 2 shows the results for H2. While the coefficient of initial enhancement level $q_{i k}$ is positive and significant $\left(\gamma_{1}=0.129, p<0.01\right)$, the coefficient of $\left(q_{i k}\right)^{2}$ is negative and significant $\left(\gamma_{2}=-0.002, p<0.01\right)$. We also calculate the turning point as $q_{i k}=26.01$ and its $95 \%$ confidence interval as $(22.15,29.36)$, and both the turning point and its confidence interval are 
Table 4 Results of probit and IV models.

\begin{tabular}{|c|c|c|c|c|c|}
\hline & $\begin{array}{c}\text { Probit Model 1 } \\
\text { Product improvement }\end{array}$ & $\begin{array}{c}\text { Probit Model } 2 \\
\text { Campaign success }\end{array}$ & $\begin{array}{l}\frac{\text { First Stage of IV Models }}{\underline{1 \text { and } 2}} \\
\text { Initial enhancement level }\end{array}$ & $\begin{array}{c}\frac{\text { Second Stage of IV }}{\text { Model } 1} \\
\text { Product improvement }\end{array}$ & $\begin{array}{c}\frac{\text { Second Stage of IV }}{\text { Model } 2} \\
\text { Campaign success }\end{array}$ \\
\hline Initial enhancement level & $\begin{array}{c}.072 * * * \\
(.004)\end{array}$ & $\begin{array}{c}.088 * * * \\
(.004)\end{array}$ & & $\begin{array}{l}.103 * * * \\
(.009)\end{array}$ & $\begin{array}{c}.129 * * * \\
(.01)\end{array}$ \\
\hline $\begin{array}{l}\text { Initial enhancement level } \times \\
\text { Initial enhancement level }\end{array}$ & $\begin{array}{c}-.002 * * * \\
(.000)\end{array}$ & $\begin{array}{c}-.002 * * * \\
(.000)\end{array}$ & & $\begin{array}{c}-.002 * * * \\
(.000)\end{array}$ & $\begin{array}{c}-.002 * * * \\
(.000)\end{array}$ \\
\hline Category: Technology & $\begin{array}{c}.059 * * * \\
(.023)\end{array}$ & $\begin{array}{l}.025 \\
(.021)\end{array}$ & $\begin{array}{l}1.004 * * * \\
(.104)\end{array}$ & $\begin{array}{l}.026 \\
(.025)\end{array}$ & $\begin{array}{l}-.016 \\
(.022)\end{array}$ \\
\hline Goal $(\ln )$ & $\begin{array}{l}-.006 \\
(.008)\end{array}$ & $\begin{array}{c}-.331 * * * \\
(.008)\end{array}$ & $\begin{array}{l}.579 * * * \\
(.034)\end{array}$ & $\begin{array}{c}-.023 * * * \\
(.009)\end{array}$ & $\begin{array}{c}-.354 * * * \\
(.009)\end{array}$ \\
\hline Duration & $\begin{array}{c}.003 * * * \\
(.001)\end{array}$ & $\begin{array}{r}-.002 * \\
(.001)\end{array}$ & $\begin{array}{c}-.019 * * * \\
(.005)\end{array}$ & $\begin{array}{c}.003 * * * \\
(.001)\end{array}$ & $\begin{array}{l}-.001 \\
(.001)\end{array}$ \\
\hline Pledge price & $\begin{array}{c}0 \\
(.000)\end{array}$ & $\begin{array}{c}0 * * * \\
(.000)\end{array}$ & $\begin{array}{c}0 \\
(.000)\end{array}$ & $\begin{array}{c}0 \\
(.000)\end{array}$ & $\begin{array}{l}0 * * * \\
(.000)\end{array}$ \\
\hline Delivery time & $\begin{array}{l}.002 \\
(.002)\end{array}$ & $\begin{array}{c}-.005^{* *} \\
(.002)\end{array}$ & $\begin{array}{l}.011 \\
(.01)\end{array}$ & $\begin{array}{l}.002 \\
(.002)\end{array}$ & $\begin{array}{c}-.005 * * \\
(.002)\end{array}$ \\
\hline Videos & $\begin{array}{l}.015 \\
(.012)\end{array}$ & $\begin{array}{l}-.005 \\
(.012)\end{array}$ & $\begin{array}{c}.696^{* * * *} \\
(.089)\end{array}$ & $\begin{array}{l}-.006 \\
(.014)\end{array}$ & $\begin{array}{c}-.032 * * \\
(.013)\end{array}$ \\
\hline Pictures & $\begin{array}{c}.013 * * * \\
(.001)\end{array}$ & $\begin{array}{c}.033^{* * * *} \\
(.001)\end{array}$ & $\begin{array}{c}.296^{* * * *} \\
(.006)\end{array}$ & $\begin{array}{l}.004 \\
(.003)\end{array}$ & $\begin{array}{l}.022 * * * \\
(.003)\end{array}$ \\
\hline Risk-section length & $\begin{array}{l}0 * * * \\
(.000)\end{array}$ & $\begin{array}{l}0 * * * \\
(.000)\end{array}$ & $\begin{array}{c}.015^{* * * *} \\
(.001)\end{array}$ & $\begin{array}{c}0 \\
(.000)\end{array}$ & $\begin{array}{l}0 * * \\
(.000)\end{array}$ \\
\hline Creator experience & $\begin{array}{l}.02 \\
(.015)\end{array}$ & $\begin{array}{c}.257 * * * \\
(.023)\end{array}$ & $\begin{array}{c}.203 * * * \\
(.062)\end{array}$ & $\begin{array}{c}.018 \\
(.015)\end{array}$ & $\begin{array}{c}.257 * * * \\
(.023)\end{array}$ \\
\hline Individual & $\begin{array}{c}-.14 * * * \\
(.024)\end{array}$ & $\begin{array}{c}-.357 * * * \\
(.02)\end{array}$ & $\begin{array}{c}-.04 \\
(.107)\end{array}$ & $\begin{array}{c}-.14 * * * \\
(.024)\end{array}$ & $\begin{array}{c}-.36^{* * * *} \\
(.02)\end{array}$ \\
\hline Competition & $\begin{array}{c}-1.274 * * * \\
(.250)\end{array}$ & $\begin{array}{c}-2.056^{* * * *} \\
(.283)\end{array}$ & $\begin{array}{c}-2.543^{*} \\
(1.405)\end{array}$ & $\begin{array}{c}-.595 * * \\
(.303)\end{array}$ & $\begin{array}{c}-1.163^{* * * *} \\
(.327)\end{array}$ \\
\hline Before relaxation of rules & & & $\begin{array}{c}3.513 * * * \\
(.153)\end{array}$ & & \\
\hline Residuals & & & & $\begin{array}{c}-.031^{* * *} * \\
(.009)\end{array}$ & $\begin{array}{c}-.04 * * * \\
(.009)\end{array}$ \\
\hline Residuals $\times$ Residuals & & & & $\begin{array}{c}0 \\
(.000)\end{array}$ & $\begin{array}{c}0^{*} \\
(.000)\end{array}$ \\
\hline Constant & $\begin{array}{c}-1.04 * * * \\
(.084)\end{array}$ & $\begin{array}{c}2.261 * * * \\
(.074)\end{array}$ & $\begin{array}{c}-2.292 * * * \\
(.366)\end{array}$ & $\begin{array}{c}-1.095^{* * *} \\
(.087)\end{array}$ & $\begin{array}{c}2.192^{* * * *} \\
(.078)\end{array}$ \\
\hline Wald $\chi^{2}$ & 1490.12 & 4034.94 & 13279.55 & 1495.50 & 4001.20 \\
\hline $\begin{array}{l}\text { pseudo } R^{2} \\
\text { Observations }\end{array}$ & $\begin{array}{c}.056 \\
18173\end{array}$ & $\begin{array}{c}.204 \\
18173\end{array}$ & $\begin{array}{c}.399 \\
18173\end{array}$ & $\begin{array}{c}.057 \\
18173\end{array}$ & $\begin{array}{c}.206 \\
18173\end{array}$ \\
\hline
\end{tabular}

within the data range. As Figure 5(d) illustrates, this result shows that as the initial enhancement level increases, the likelihood of campaign success first increases but then decreases. Thus, like Probit Model 2, IV Model 2 does not support H2. In §4, we discuss a possible explanation for this relationship between the initial enhancement level and campaign success.

Table 4 also shows that in the second stage of both IV models, the coefficients of residuals obtained from the first-stage model are negative and significant. Significant residuals confirm a possible endogeneity problem and support our use of an IV (Wooldridge 2010).

Robustness Check. To check the robustness of our empirical results, we also run spline regressions, which use knots to capture the different impact of an explanatory variable for different intervals (e.g., Kesavan et al. 2014). We try various spline regressions for the second-stage estimations in both IV models, and we find that the coefficient of the first spline is positive and significant and the coefficient of the second spline is negative and significant (see Table EC.1 in Online Appendix EC.2), supporting our results above. 


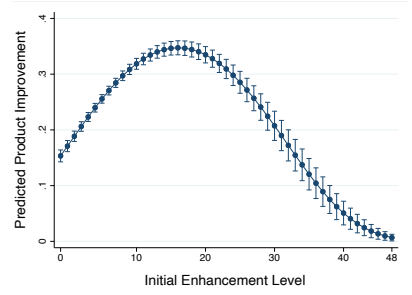

(a) Probit Model 1.

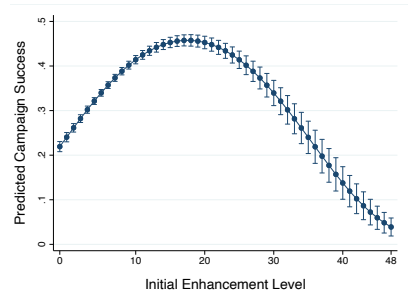

(b) Probit Model 2.

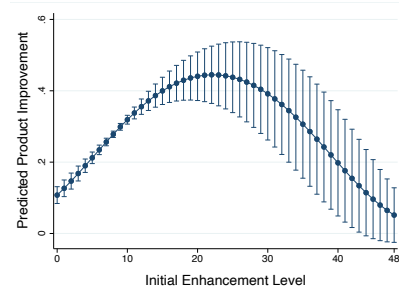

(c) IV Model 1.

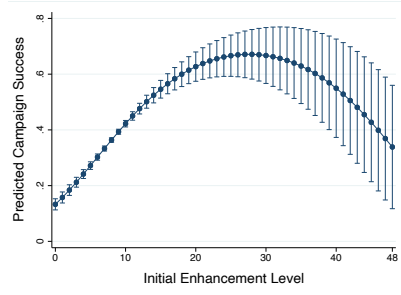

(d) IV Model 2.

Figure 5 Predicted likelihood of product improvement and campaign success.

Additionally, we run our empirical models for the following cases (see Online Appendix EC.2 for details). First, to have equal time periods before and after the instrument, we exclude campaigns launched after April 28, 2015, and we show the robustness of our empirical findings by analyzing 11,764 campaigns. Second, we observe that in some campaigns, the number of topics in the final description of a product is slightly lower than in the initial description, often because of the decrease in the length of the description. When we exclude these campaigns and analyze 17,005 campaigns, our results continue to hold. Third, we treat cancelled campaigns as failed campaigns, and show the robustness of our findings by analyzing 21,184 campaigns. Fourth, as we explain in Appendix B.1, we train the LDA model with 50 topics, in line with the literature. Our results continue to hold when we set the number of topics to $20 \%$ above or below 50 in the LDA model and when we set the threshold to $20 \%$ above or below 10 words when counting the number of topics in each description. Finally, when testing H1, we control for the average competition in the first week of each campaign instead of the average competition during the campaign to avoid timing problem, and we show that our results hold.

\section{Revised Theoretical Model and Analysis}

Our empirical results do not support $\mathrm{H} 2$, and suggest that $\mathbb{P}$ (success) first increases and then decreases with the initial enhancement level. This discrepancy between the normative theory and empirical findings may suggest some behavioral effects. Specifically, when enhancing the product, a creator may end up with a too complex or too advanced product, which can overwhelm customers (e.g., Mick and Fournier 1998) or can lead to customer anxiety (e.g., Castaño et al. 2008, Goodman and Irmak 2013). To factor in such behavioral effects, we incorporate a cost of $b \cdot q_{f}^{2}$ into each customer's utility, where $b>0$, and this cost discounts the value that each customer receives from the product enhancement. Specifically, we modify the utility function of customer $j(\in\{1,2\})$ in $\S 2$ as follows:

$$
U_{j}=v_{j}\left(q_{f}-b \cdot q_{f}^{2}\right)-p, \text { where } q_{f}=q_{i} \text { or } q_{f}=q_{i}+q_{u} .
$$

Note that when we omit behavioral effects, i.e., the behavioral cost parameter $b=0$, this model boils down to our original model in $\S 2$. 


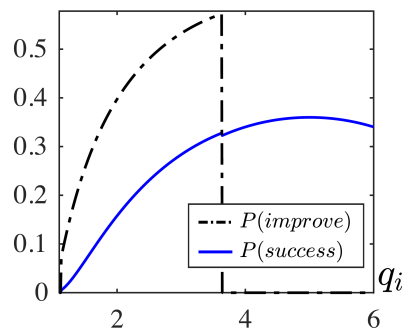

Figure 6 The impact of $q_{i}$ on $\mathbb{P}($ improve $)$ and $\mathbb{P}($ success $)$. The setting is the same as in Figure 3 where $b=0.1$.

Considering $U_{j}$ in $(2)$, we use the same approach in $\S 2$ to analyze the impact of $q_{i}$ on $\mathbb{P}($ improve $)$ and $\mathbb{P}$ (success), and obtain the following proposition. ${ }^{19}$

Proposition 3. (a) There exists a threshold $\overline{q_{i}}(\geq 0)$ such that when the initial enhancement level $q_{i} \leq \overline{q_{i}}, \mathbb{P}($ improve $)=\frac{\left(q_{i}+q_{u}\right)-b\left(q_{i}+q_{u}\right)^{2}-p}{\left(q_{i}+q_{u}\right)-b\left(q_{i}+q_{u}\right)^{2}}$, which is increasing in $q_{i}$ if and only if $b\left(q_{i}+q_{u}\right)<0.5$. Furthermore, there exists $\underline{q_{i}}\left(\in \mathbb{R}_{+} \cup\{+\infty\}\right)$ such that when $q_{i}>\underline{q_{i}}, \mathbb{P}($ improve $)=0$.

(b) There exist thresholds $q_{i}^{\prime}(\geq 0)$ and $q_{i}^{\prime \prime}\left(\in \mathbb{R}_{+} \cup\{+\infty\}\right)$ such that $\mathbb{P}$ (success) is increasing in $q_{i}<q_{i}^{\prime}$ and $\mathbb{P}($ success $)$ is decreasing in $q_{i}>q_{i}^{\prime \prime}$.

As Figure 6 illustrates, Proposition 3(a) extends Proposition 1 to the case where $U_{j}$ is as in (2). In this case, as $q_{i}$ increases, $\mathbb{P}($ improve $)$ first increases and may then decrease before $\mathbb{P}($ improve $)=0$.

More importantly, Proposition 3(b) shows that $\mathbb{P}$ (success) increases with the initial enhancement level $q_{i}$ when $q_{i}$ is below a certain threshold, and that $\mathbb{P}$ (success) decreases with $q_{i}$ when $q_{i}$ is above a certain threshold; see Figure 6. (Note that in Figure 6, thresholds $q_{i}^{\prime}$ and $q_{i}^{\prime \prime}$ in Proposition 3(b) overlap.) The reason is that, although each customer's utility increases with $q_{i}$ up to some point, too large an increase in $q_{i}$ reduces each customer's utility, and it thus becomes less likely that customers will pledge. Therefore, when we consider the customer's utility in (2), our theoretical predictions and empirical observations become consistent.

Proposition 3(b) has the following interesting implication for crowdfunding practice. As we discuss in $\S 1$, Kickstarter experts suggest enhancing the product as much as possible before campaign launch (Kickstarter 2021e) by assuming that a more enhanced product is more likely to be successful. However, we show that this assumption does not necessarily hold. Instead, to run a successful campaign, a creator should avoid enhancing the product too much before the campaign as it can overwhelm customers or can lead to customer anxiety.

\footnotetext{
${ }^{19}$ In $\S 4$ and $\S 5$, we assume that $q_{f}-b q_{f}^{2}-p>0$, where $q_{f}=q_{i}$ (respectively, $q_{f}=q_{i}+q_{u}$ ), to avoid trivial cases where even a customer with maximum valuation does not pledge when there is no improvement (respectively, there is an improvement).
} 


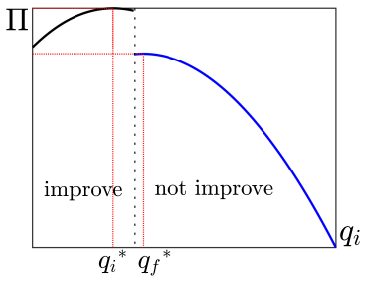

(a) $C_{i}=0.05$.

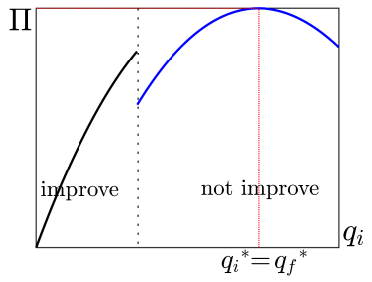

(b) $C_{i}=0.01$.

Figure 7 The creator's ex-ante expected profit $\Pi$ in Stage 0 as a function of $q_{i}$. The left-hand side of the figures represents $q_{i}$ 's which lead to improvement (i.e., $I \geq 0$ ) and the right-hand side represents $q_{i}$ 's which lead to no improvement (i.e., $I<0$ ). The setting is the same as in Figure 6(a).

\section{Optimal Level of Enhancement at Campaign Launch}

So far, to answer our first two research questions (Q1) and (Q2), we have considered the case in which the initial enhancement level $q_{i}$ is exogenously given. We now consider the optimal initial enhancement level to answer our last research question (Q3). For this analysis, we use our revised model in $\S 4$ as it yields predictions that are consistent with our empirical observations in $\S 3.4$.

We build on the backward induction argument presented in $\S 2.1$ to derive the sub-game perfect equilibrium. When customer $j$ 's utility $U_{j}$ is as in (2), the creator improves the product during the campaign for any $q_{i}$ if and only if

$$
I \equiv \frac{p^{2}\left(1-b\left(2 q_{i}+q_{u}\right)\right)}{q_{i}\left(q_{i}+q_{u}\right)\left(1-b\left(q_{i}+q_{u}\right)\right)\left(1-b q_{i}\right)}-c\left(2 q_{i}+q_{u}-\frac{p}{\left(1-b\left(q_{i}+q_{u}\right)\right)\left(1-b q_{i}\right)}\right) \geq 0 .
$$

This condition is analogous to the one in (1). Given this condition, in Stage 0 of our revised model, the creator decides on $q_{i}$ that maximizes the following profit:

$$
\Pi=\left\{\begin{array}{l}
\left(1-\frac{p}{\left(q_{i}+q_{u}\right)-b\left(q_{i}+q_{u}\right)^{2}}\right)^{2}\left(2 p-2 c\left(q_{i}+q_{u}\right)^{2}\right)-C_{i} q_{i}, \text { if } I \geq 0, \\
\left(1-\frac{p}{q_{i}-b q_{i}^{2}}\right)^{2}\left(2 p-2 c q_{i}^{2}\right)-C_{i} q_{i}, \text { otherwise. }
\end{array}\right.
$$

Let $q_{i}^{*}$ and $q_{f}^{*}$ be the optimal initial and final enhancement levels of the product respectively, where $q_{f}^{*}=q_{i}^{*}+q_{u}$ or $q_{f}^{*}=q_{i}^{*}$, depending whether $I \geq 0$ or $I<0$ under $q_{i}^{*}$. To analyze whether it is always optimal for the creator to enhance the product as much as possible before the campaign (i.e., $q_{i}^{*}=q_{f}^{*}$ ), we make the following mild assumption.

Assumption 1. $q_{u}-b q_{u}^{2}-p>0$ and $p-c q_{u}^{2}>0$.

This assumption ensures that the cost of an improvement during a campaign can be recovered at least under zero initial enhancement so that making an improvement is an option for the creator. Under Assumption 1, we analyze the relationship between $q_{i}^{*}$ and $q_{f}^{*}$ in the following proposition.

Proposition 4. For any $b(\geq 0)$, there exists a threshold $\underline{C_{i}}(\geq 0)$ such that if $C_{i}>\underline{C_{i}}$, then $q_{i}^{*}=q_{f}^{*}-q_{u}$. 
As we discuss in $§ 1$, experts on crowdfunding campaigns suggest that products should be enhanced as much as possible before campaigns (i.e., $q_{i}^{*}=q_{f}^{*}$ ), yet Proposition 4 shows that this is not the optimal strategy for a creator when $C_{i}$ is above a threshold. ${ }^{20}$ The intuition is as follows. As $C_{i}$ increases, it becomes more costly for the creator to increase $q_{i}$. Thus, to save on the initial investment cost, the creator prefers setting $q_{i}^{*}=q_{f}^{*}-q_{u}$ and improves the product during the campaign, as Figure 7(a) illustrates. Note that this result continues to hold even when there is no behavioral effect that leads the customer's utility to decrease with $q_{i}$, i.e., when $b=0$. This result suggests that if enhancing the product fully before launching a campaign would entail significant additional costs for the creator, it may be better to go ahead with a basic version of a product and improve it during the campaign, even though this may decrease the chances of the campaign being successful. These additional costs might relate to market research, concept generation, design rework, or engineering changes. We also illustrate in Figure $7(\mathrm{~b})$ that when $C_{i}$ is small, the creator enhances the product fully (i.e., $q_{i}^{*}=q_{f}^{*}$ ) without leaving any room for further improvements during the campaign.

\section{Discussion and Conclusion}

Crowdfunding is more than just an effective financing instrument for entrepreneurs. One of its key advantages, which has received cursory attention from the crowdfunding literature, is that it enables creators to improve their products in response to customer feedback (Mollick 2014, Cornelius and Gokpinar 2020). To take advantage of this, a creator may launch a crowdfunding campaign for a basic version of a product (i.e., product with fewer features), leaving room for it to be improved. However, if the product appears too basic, customers may not pledge and the campaign may thus fail. Keen to investigate this key trade-off, we study how the initial enhancement level of a product affects the likelihood of it being improved during a campaign and the chances of the campaign being successful, and we ultimately analyze whether a creator should enhance a product as much as possible before launching a crowdfunding campaign.

Inspired by both crowdfunding practice and literature (e.g., Hu et al. 2015, Belavina et al. 2020, Chakraborty and Swinney 2021), we construct a parsimonious game-theoretical model of rewardbased, all-or-nothing crowdfunding that takes into account the creator's product improvement decision. We obtain the following results. Although one might expect that more enhanced products are less likely to be improved since this will increase the creator's production cost, we show that this is only true when there is extensive initial enhancement. In contrast, when there is relatively little initial enhancement, the likelihood of product improvement increases with the initial enhancement level, because customers are then more likely to pledge and to leave comments. We also show the

\footnotetext{
${ }^{20}$ Our additional analysis shows that when $b=0, q_{i}^{*}=q_{f}^{*}-q_{u}$ if and only if $C_{i}>\underline{C_{i}}$. Otherwise, $q_{i}^{*}=q_{f}^{*}$.
} 
intuitive result that as the initial enhancement level increases, the likelihood of campaign success increases, but at a decreasing rate when the initial enhancement level is high.

We test these theoretical predictions using a unique data set from Kickstarter. Our empirical findings support the predicted relationship between the initial enhancement level (i.e., number of features) and the likelihood of product improvement. More interestingly, although our theoretical model intuitively predicts that the likelihood of campaign success will increase with the initial enhancement level, our empirical finding does not support this prediction. Instead, we show that the likelihood of campaign success at first increases but then, counterintuitively, decreases with the initial enhancement level. This can be because a highly enhanced product can be too complex or too advanced, which can overwhelm customers (e.g., Mick and Fournier 1998) or may lead to customer anxiety (e.g., Castaño et al. 2008). This result suggests that to run a successful campaign, the creator should avoid enhancing the product too much before the campaign.

Building on these results, we test the experts' recommended strategy of enhancing the product as much as possible before the campaign, and we show that this strategy is not always optimal. Instead, when customer involvement can reduce the product development costs - such as for market research, concept generation, design rework, or engineering changes - it can be better for the creator to go ahead with a simple version of a product and make improvements to it during the campaign, even though this may decrease the chances of the campaign being successful.

Our results not only contribute to the crowdfunding literature, but also add to the NPD literature (cf. Krishnan and Ulrich 2001, Loch and Kavadias 2008), as we revisit the debate around flexible approaches in product development and the role of customer feedback. Specifically, we point out that unlike traditional product development approaches (e.g., Bhattacharya et al. 1998, Thomke and Reinertsen 1998), crowdfunding enables a creator to improve a product based on customer feedback before committing to any production. Although this approach comes with a risk of campaign failure, our results suggest that it can still be better for the creator to leave scope to refine the product based on customer feedback during the campaign.

Our paper is a first step towards analyzing creators' product development and improvement decisions in crowdfunding campaigns, so it naturally has some limitations that provide opportunities for future research. First, when analyzing how the initial enhancement level of a product affects a campaign's chances of success, we measure this by comparing the funds raised at the end of the campaign to the funding goal. Although this measure is consistent with our theoretical model and appropriate for the purpose of our study, it would also be interesting to analyze the impact of the initial enhancement level of a product on the likelihood of it being delivered to customers (i.e., a successful product launch). This analysis would require a more comprehensive data set that includes product launch information. Second, inspired by practice, in our theoretical model, we 
consider customer comments as providing a motivation for the creator to improve the product during the campaign, and we focus on the creator's decisions on the initial enhancement level of a product and whether to improve it during the campaign. However, an interesting direction for future research would be to focus in detail on customers' pledging and commenting decisions. Finally, our study focuses on reward-based crowdfunding, but it would also be interesting to analyze the impact of the initial enhancement level of a product in equity-based crowdfunding where customer and creator dynamics can be quite different.

\section{References}

Agrawal, A., C. Catalini, A. Goldfarb. 2015. Crowdfunding: Geography, social networks, and the timing of investment decisions. Journal of Economics \& Management Strategy 24(2) 253-274.

Allon, G., V. Babich. 2020. Crowdsourcing and crowdfunding in the manufacturing and services sectors. Manufacturing \& Service Operations Management 22(1) 102-112.

Althuizen, N., B. Chen. 2021. Crowdsourcing ideas using product prototypes: The joint effect of prototype enhancement and the product design goal on idea novelty. Management Science Forthcoming.

Angrist, J. D., J. S. Pischke. 2009. Mostly harmless econometrics: An Empiricist's Companion. Princeton University Press, Princeton, NJ.

Babich, V., S. Marinesi, G. Tsoukalas. 2021. Does crowdfunding benefit entrepreneurs and venture capital investors? Manufacturing \& Service Operations Management 66(11) 4980-4997.

Belavina, E., S. Marinesi, G. Tsoukalas. 2020. Rethinking crowdfunding platform design: Mechanisms to deter misconduct and improve efficiency. Management Science 66(11) 4980-4997.

Belleflamme, P., T. Lambert, A. Schwienbacher. 2014. Crowdfunding: Tapping the right crowd. Journal of Business Venturing 29(5) 585-609.

Bellstam, G., S. Bhagat, J. A. Cookson. 2020. A text-based analysis of corporate innovation. Management Science, Forthcoming.

Bhaskaran, S., S. S. Erzurumlu, K. Ramachandran. 2020. Sequential product development and introduction by cash-constrained start-ups. Manufacturing $\& 3$ Service Operations Management, Forthcoming.

Bhattacharya, S., V. Krishnan, V. Mahajan. 1998. Managing new product definition in highly dynamic environments. Management Science 44(11) 50-64.

Bi, G., B. Geng, L. Liu. 2019. On the fixed and flexible funding mechanisms in reward-based crowdfunding. European Journal of Operational Research 279(1) 168-183.

Blaseg, D., C. Schulze, B. Skiera. 2020. Consumer protection on Kickstarter. Marketing Science 39(1) $211-233$.

Blei, D. M., A. Y. Ng, M. I. Jordan. 2003. Latent Dirichlet allocation. Journal of Machine Learning Research 3 993-1022.

Burtch, G., A. Ghose, S. Wattal. 2013. An empirical examination of the antecedents and consequences of contribution patterns in crowd-funded markets. Information Systems Research 24(3) 499-519. 
Burtch, G., D. Gupta, P. Martin. 2020. Referral timing and fundraising success in crowdfunding. Manufacturing $\&$ Service Operations Management, Forthcoming.

Castaño, R., M. Sujan, M. Kacker, H. Sujan. 2008. Managing consumer uncertainty in the adoption of new products: Temporal distance and mental simulation. Journal of Consumer Research 45(3) 320-336.

Chakraborty, S., R. Swinney. 2019. Designing rewards-based crowdfunding campaigns for strategic (but distracted) contributors. Working Paper, Duke University, Durham.

Chakraborty, S., R. Swinney. 2021. Signaling to the crowd: Private quality information and rewards-based crowdfunding. Manufacturing \& Service Operations Management 23(1) 155-169.

Chan, T. H., J. Mihm, M. Sosa. 2020. Revisiting the role of collaboration in creating breakthrough inventions. Manufacturing $\&$ Service Operations Management Forthcoming.

Chemla, G., K. Tinn. 2020. Learning through crowdfunding. Managemet Science 66(5) 1783-1801.

Chen, Y.-J., T. Dai, C. G. Korpeoglu, E. Körpeoğlu, O. Sahin, C. S. Tang, S. Xiao. 2020. OM Foruminnovative online platforms: Research opportunities. Manufacturing \& Service Operations Management 22 (3) 430-445.

Cohen, M. A., J. Eliashberg, T.-H. Ho. 1996. New product development: The performance and time-tomarket tradeoff. Management Science 42(2) 173-186.

Cornelius, P. B., B. Gokpinar. 2020. The role of customer investor involvement in crowdfunding success. Management Science 66(1) 452-472.

Du, L., M. Hu, J. Wu. 2017. Contingent stimulus in crowdfunding. Working Paper, University of Toronto, Toronto.

Erat, S., S. Kavadias. 2008. Sequential testing of product designs: Implications for learning. Management Science 54(5) 956-968.

Gao, F., S. Cui, M. Cohen. 2021. Performance, reliability, or time-to-market? Innovative product development and the impact of government regulation. Production and Operations Management 30(1) 253-275.

Ghose, A., P. G. Ipeirotis, B. Li. 2019. Modeling consumer footprints on search engines: An interplay with social media. Management Science 65(3) 1363-1385.

Goodman, J. K., C. Irmak. 2013. Having versus consuming: Failure to estimate usage frequency makes consumers prefer multifeature products. Journal of Marketing Research 50(1) 44-54.

Griffiths, T. L., M. Steyvers. 2004. Finding scientific topics. Proceedings of the National academy of Sciences $1015228-5235$.

Guo, L., J. Zhang. 2012. Consumer deliberation and product line design. Marketing Science 31(6) 995-1007.

Haans, R. F. J., C. Pieters, Z.-L. He. 2016. Thinking about U: Theorizing and testing U- and inverted U-shaped relationships in strategy research. Strategic Management Journal 37(7) 1177-1195.

Hu, M., X. Li, M. Shi. 2015. Product and pricing decisions in crowdfunding. Marketing Science 34(3) $331-345$.

Kesavan, S., B. R. Staats, W. Gilland. 2014. Volume flexibility in services: The costs and benefits of flexible labor resources. Management Science 60(8) 1884-1906.

Kickstarter. 2021a. HAIZE - minimalist urban bike navigation. http://www.kickstarter.com/projects/ onomo/haize-a-compass-reinvented-navigation-for-urban-cy. Accessed on February 12, 2021. 
Kickstarter. 2021b. How can I cancel my project? http://help.kickstarter.com/hc/en-us/articles/ 115005138393-How-can-I-cancel-my-project-. Accessed on February 22, 2021.

Kickstarter. 2021c. Introducing badges for projects we love. http://www.kickstarter.com/blog/ introducing-projects-we-love-badges. Accessed on January 1, 2021.

Kickstarter. 2021d. The Kickstarter blog: Introducing launch now and simplified rules. http://www. kickstarter.com/blog/introducing-launch-now-and-simplified-rules-0/. Accessed on January 1, 2021.

Kickstarter. 2021e. Kickstarter creator basics. http://www.youtube.com/c/kickstarter/playlists. Accessed on February 13, 2021.

Kickstarter. 2021f. Sphericam 2, the 4k $360^{\circ}$ Video Camera for VR. http://www.kickstarter.com/projects/ 1996234044/sphericam-2-the-4k-360o-video-camera-for-virtual-r/comments. Accessed on January 8, 2021.

Kickstarter. 2021g. Stats. http://www.kickstarter.com/help/stats. Accessed on January 1, 2021.

Kickstarter. 2021h. What do i do if i have questions about a project? http://help.kickstarter.com/hc/ en-us/articles/115005126314-What-do-I-do-if-I-have-questions-about-a-project-. Accessed on August $3,2021$.

Krishnan, V., K. Ramachandran. 2011. Integrated product architecture and pricing for managing sequential innovation. Management Science 57(11) 2040-2053.

Krishnan, V., K. T. Ulrich. 2001. Product development decisions: A review of the literature. Management Science 47(1) 1-21.

Kuppuswamy, V., B. L. Bayus. 2017. Does my contribution to your crowdfunding project matter? Journal of Business Venturing 32(1) 72-89.

Li, Z., J. A. Duan, S. Ransbotham. 2020. Coordination and dynamic promotion strategies in crowdfunding with network externalities. Production and Operations Management 29(4) 1032-1049.

Lin, M., S. Viswanathan. 2016. Home bias in online investments: An empirical study of an online crowdfunding market. Management Science 62(5) 1393-1414.

Loch, C., S. Kavadias. 2008. Handbook of new product development management. Butterworth-Heinemann, Oxford, UK.

Loch, C. H., C. Terwiesch, S. Thomke. 2001. Parallel and sequential testing of design alternatives. Management Science 47(5) 663-678.

Masters, T. 2013. Marillion 'understood where the internet was going early on'. BBC News .

Mick, D. G., S. Fournier. 1998. Paradoxes of technology: Consumer cognizance, emotions, and coping strategies. Journal of Consumer Research 25(2) 123-143.

Mollick, E. 2014. The dynamics of crowdfunding: An exploratory study. Journal of Business Venturing 29(1) $1-16$.

Mollick, E. 2016. The unique value of crowdfunding is not money - it's community. Harvard Business Review http://hbr.org/2016/04/the-unique-value-of-crowdfunding-is-not-money-its-community.

Mollick, E., R. Nanda. 2016. Wisdom or madness? Comparing crowds with expert evaluation in funding the arts. Management Science 62(6) 1533-1553. 
Özer, Ö., O. Uncu. 2013. Competing on time: An integrated framework to optimize dynamic time-to-market and production decisions. Production and Operations Management 22(3) 473-488.

Petrin, T., K. Train. 2010. A control function approach to endogeneity in consumer choice models. Journal of Marketing Research 47(1) 3-13.

Roma, P., E. Gal-Or, R. R. Chen. 2018. Reward-based crowdfunding campaigns: Informational value and access to venture capital. Information Systems Research 29(3) 679-697.

Sommer, S. C., C. H. Loch, J. Dong. 2009. Managing complexity and unforeseeable uncertainty in startup companies: An empirical study. Organization Science 20(1) 118-133.

Sorenson, O., V. Assenova, G.-C. Li, J. Boada, L. Fleming. 2016. Expand innovation finance via crowdfunding. Science 354(6319) 1526-1528.

Steyvers, M., T. Griffiths. 2007. Probabilistic topic models. Handbook of latent semantic analysis 427(7) $424-440$.

Strausz, R. 2017. A theory of crowdfunding: A mechanism design approach with demand uncertainty and moral hazard. American Economic Review 107(6) 1430-1476.

Tan, T. F., S. Netessine. 2019. When you work with a superman, will you also fly? An empirical study of the impact of coworkers on performance. Management Science 65(8) 3495-3517.

Thomke, S., D. E. Bell. 2001. Sequential testing in product development. Management Science 47(2) 308-323.

Thomke, S., D. Reinertsen. 1998. Agile product development: Managing development flexibility in uncertain environments. California Management Review 41(1) 8-30.

Tirunillai, S., G. J. Tellis. 2014. Mining marketing meaning from online chatter: Strategic brand analysis of big data using latent Dirichlet allocation. Journal of Marketing Research 51(4) 463-479.

Toubia, O., G. Iyengar, R. Bunnell, A. Lemaire. 2019. Extracting features of entertainment products: A guided latent Dirichlet allocation approach informed by the psychology of media consumption. Journal of Marketing Research 56(1) 18-36.

Ulrich, K. T., S. D. Eppinger. 2016. Product Design and Development. McGraw-Hill Education, New York, NY.

Wei, X., M. Fan, W. You, Y. Tan. 2020. An empirical study of the dynamic and differential effects of prefunding. Production and Operations Management, Forthcoming.

Wooldridge, J. M. 2010. Econometric Analysis of Cross Section and Panel Data. MIT Press, Cambridge, MA.

Wooldridge, J. M. 2015. Control function methods in applied econometrics. The Journal of Human Resources 50(2) 420-445.

\section{Appendix}

In Appendix A, we present the proofs; and in Appendix B, we provide additional discussions. 


\section{A. Proofs}

Proof of Lemma 1. From (1), suppose that $\frac{p^{2}}{q_{i}\left(q_{i}+q_{u}\right)}-c\left(2 q_{i}+q_{u}-p\right) \geq 0$. Then, the creator's expected profit is as follows:

$$
\begin{aligned}
\Pi & =\underbrace{\mathbb{P}\left(v_{1} \geq \max \left\{\frac{p}{q_{i}+q_{u}}, \frac{p^{2}}{q_{i}\left(q_{i}+q_{u}\right)}\right\}\right)}_{\text {customer 1 pledges and makes a comment }} \cdot \underbrace{\mathbb{P}\left(v_{2} \geq \frac{p}{q_{i}+q_{u}}\right)}_{\text {customer 2 pledges }}\left(2 p-2 c\left(q_{i}+q_{u}\right)^{2}\right)-C_{i} q_{i} \\
& =\left(\frac{q_{i}+q_{u}-p}{q_{i}+q_{u}}\right)^{2}\left(2 p-2 c\left(q_{i}+q_{u}\right)^{2}\right)-C_{i} q_{i} .
\end{aligned}
$$

In this case, $\mathbb{P}($ improve $)=\frac{q_{i}+q_{u}-p}{q_{i}+q_{u}}$ and $\mathbb{P}($ success $)=\left(\frac{q_{i}+q_{u}-p}{q_{i}+q_{u}}\right)^{2}$. Next, suppose that $\frac{p^{2}}{q_{i}\left(q_{i}+q_{u}\right)}-$ $c\left(2 q_{i}+q_{u}-p\right)<0$. Then, the creator's expected profit is as follows:

$$
\Pi=\left(\frac{q_{i}-p}{q_{i}}\right)^{2}\left(2 p-2 c q_{i}^{2}\right)-C_{i} q_{i} .
$$

In this case, $\mathbb{P}($ improve $)=0$ and $\mathbb{P}($ success $)=\left(\frac{q_{i}-p}{q_{i}}\right)^{2}$.

Proof of Proposition 1. The first derivative of the left hand-side of the condition in (1) is

$$
\frac{\partial\left(\frac{p^{2}}{q_{i}\left(q_{i}+q_{u}\right)}-c\left(2 q_{i}+q_{u}-p\right)\right)}{\partial q_{i}}=-\frac{p^{2}\left(2 q_{i}+q_{u}\right)}{\left(q_{i}\left(q_{i}+q_{u}\right)\right)^{2}}-2 c<0,
$$

and we have $\lim _{q_{i} \rightarrow 0} \frac{p^{2}}{q_{i}\left(q_{i}+q_{u}\right)}-c\left(2 q_{i}+q_{u}-p\right)=\infty$ and $\lim _{q_{i} \rightarrow \infty} \frac{p^{2}}{q_{i}\left(q_{i}+q_{u}\right)}-c\left(2 q_{i}+q_{u}-p\right)=-\infty$. Thus, there exists $\overline{q_{i}}(\geq 0)$ such that $\frac{p^{2}}{q_{i}\left(q_{i}+q_{u}\right)}-c\left(2 q_{i}+q_{u}-p\right) \geq 0$, and hence $q_{f}=q_{i}+q_{u}$ if and only if $q_{i} \leq \overline{q_{i}}$. Also, from Lemma 1 , customer 1 pledges and makes a comment with probability $\frac{q_{i}+q_{u}-p}{q_{i}+q_{u}}$, which is increasing in $q_{i}$. Thus, the ex-ante probability that the creator improves the product during the campaign is

$$
\mathbb{P}(\text { improve })=\left(\frac{q_{i}+q_{u}-p}{q_{i}+q_{u}}\right) \cdot 1_{\left\{\frac{p^{2}}{q_{i}\left(q_{i}+q_{u}\right)}-c\left(2 q_{i}+q_{u}-p\right) \geq 0\right\}} .
$$

Therefore, if $q_{i} \leq \overline{q_{i}}, \mathbb{P}($ improve $)$ is increasing in $q_{i}$; otherwise, $\mathbb{P}($ improve $)=0$.

REMARK 1. When $\lim _{q_{i} \rightarrow p} \frac{p^{2}}{q_{i}\left(q_{i}+q_{u}\right)}-c\left(2 q_{i}+q_{u}-p\right)=\frac{p}{\left(p+q_{u}\right)}-c\left(p+q_{u}\right)>0$, i.e., $c<\frac{p}{\left(p+q_{u}\right)^{2}}$, we have $\overline{q_{i}}>0$. Also, when $c \geq \frac{p}{(p+q u)^{2}}, \overline{q_{i}}=0$, and hence $\mathbb{P}($ improve $)=0$ for any $q_{i}$.

Proof of Proposition 2. Recall that $q_{f}=q_{i}$ or $q_{f}=q_{i}+q_{u}$ depending on whether there is an improvement or not. In both cases, the first derivative of $\mathbb{P}$ (success) with respect to $q_{i}$ is $\frac{\partial \mathbb{P}(\text { success })}{\partial q_{i}}=\frac{2 p}{q_{f}^{2}}\left(\frac{q_{f}-p}{q_{f}}\right)$. Since $q_{f} \geq q_{i}>p, \frac{\partial \mathbb{P}(\text { success })}{\partial q_{i}}>0$. Also, in both cases, the second derivative of $\mathbb{P}($ success $)$ with respect to $q_{i}$ is $\frac{\partial^{2} \mathbb{P}(\text { success })}{\partial q_{i}^{2}}=2\left(-\frac{2 p}{q_{f}^{3}}+\frac{3 p^{2}}{q_{f}^{4}}\right)$, and $\frac{\partial^{2} \mathbb{P}(\text { success })}{\partial q_{i}^{2}}>0$ if and only if $q_{f}<\frac{3 p}{2}$. Recall from the proof of Proposition $1, q_{f}=q_{i}+q_{u}$ if and only if $q_{i} \leq \overline{q_{i}}$. Therefore, when $q_{i}>\underline{q_{i}}=\max \left\{\overline{q_{i}}, \frac{3 p}{2}\right\}, \mathbb{P}($ success $)$ is concave in $q_{i}$.

Proof of Proposition 3. We first identify sub-game perfect equilibrium strategies. When customer $k$ 's utility function is as in (2), in the fourth stage, if $q_{f}=q_{i}+q_{u}$, customer 2 pledges with 
probability $\frac{\left(q_{i}+q_{u}\right)-b\left(q_{i}+q_{u}\right)^{2}-p}{\left(q_{i}+q_{u}\right)-b\left(q_{i}+q_{u}\right)^{2}}$; and if $q_{f}=q_{i}$, customer 2 pledges with probability $\frac{q_{i}-b q_{i}^{2}-p}{q_{i}-b q_{i}^{2}}$. In the third stage, the creator decides whether to improve the product by comparing

$$
\begin{aligned}
& \Pi^{I}=\left(\frac{\left(q_{i}+q_{u}\right)-b\left(q_{i}+q_{u}\right)^{2}-p}{\left(q_{i}+q_{u}\right)-b\left(q_{i}+q_{u}\right)^{2}}\right)\left(2 p-2 c\left(q_{i}+q_{u}\right)^{2}\right)-C_{i} q_{i}, \text { and } \\
& \Pi^{N I}=\left(\frac{q_{i}-b q_{i}^{2}-p}{q_{i}-b q_{i}^{2}}\right)\left(2 p-2 c q_{i}^{2}\right)-C_{i} q_{i} .
\end{aligned}
$$

Thus, the creator improves the product if and only if $\Pi^{I} \geq \Pi^{N I}$, i.e.,

$$
I \equiv \frac{p^{2}\left(1-b\left(2 q_{i}+q_{u}\right)\right)}{q_{i}\left(q_{i}+q_{u}\right)\left(1-b\left(q_{i}+q_{u}\right)\right)\left(1-b q_{i}\right)}-c\left(2 q_{i}+q_{u}-\frac{p}{\left(1-b\left(q_{i}+q_{u}\right)\right)\left(1-b q_{i}\right)}\right) \geq 0 .
$$

In the second stage, when customer 1 pledges, she decides whether to make a comment or not by comparing

$$
\begin{aligned}
& U_{1}^{C}=\left(\frac{\left(q_{i}+q_{u}\right)-b\left(q_{i}+q_{u}\right)^{2}-p}{\left(q_{i}+q_{u}\right)-b\left(q_{i}+q_{u}\right)^{2}}\right)\left(v_{1}\left(\left(q_{i}+q_{u}\right)-b\left(q_{i}+q_{u}\right)^{2}\right)-p\right) \text { and } \\
& U_{1}^{N C}=\left(\frac{q_{i}-b q_{i}^{2}-p}{q_{i}-b q_{i}^{2}}\right)\left(v_{1}\left(q_{i}-b q_{i}^{2}\right)-p\right) .
\end{aligned}
$$

Thus, customer 1 makes a comment if and only if $U_{1}^{C} \geq U_{1}^{N C}$, i.e., $v_{1} \geq \frac{p^{2}}{\left(q_{i}-b q_{i}^{2}\right)\left(\left(q_{i}+q_{u}\right)-b\left(q_{i}+q_{u}\right)^{2}\right)}$. In the first stage, when customer 1 anticipates an improvement (i.e., $I \geq 0$ ), customer 1 decides whether to pledge or not by comparing

$$
U_{1}^{P}=\left(\frac{\left(q_{i}+q_{u}\right)-b\left(q_{i}+q_{u}\right)^{2}-p}{\left(q_{i}+q_{u}\right)-b\left(q_{i}+q_{u}\right)^{2}}\right)\left(v_{1}\left(\left(q_{i}+q_{u}\right)-b\left(q_{i}+q_{u}\right)^{2}\right)-p\right) \text { and } U_{1}^{N P}=0 .
$$

So, customer 1 pledges if $v_{1} \geq \frac{p}{\left(q_{i}+q_{u}\right)-b\left(q_{i}+q_{u}\right)^{2}}$. When (8) holds (i.e., $I \geq 0$ ), she pledges and makes a comment if

$$
v_{1} \geq \max \left\{\frac{p^{2}}{\left(q_{i}-b q_{i}^{2}\right)\left(\left(q_{i}+q_{u}\right)-b\left(q_{i}+q_{u}\right)^{2}\right)}, \frac{p}{\left(q_{i}+q_{u}\right)-b\left(q_{i}+q_{u}\right)^{2}}\right\}=\frac{p}{\left(q_{i}+q_{u}\right)-b\left(q_{i}+q_{u}\right)^{2}} .
$$

Note that the equality in (9) holds because $\frac{p}{q_{i}-b q_{i}^{2}}<1$. So, when $I \geq 0$, customer 1 makes a comment whenever she pledges. In the first stage, when $I<0$, customer 1 decides whether to pledge or not by comparing $U_{1}^{P}=\left(\frac{q_{i}-b q_{i}^{2}-p}{q_{i}-b q_{i}^{2}}\right)\left(v_{1}\left(q_{i}-b q_{i}^{2}\right)-p\right)$ and $U_{1}^{N P}=0$. Thus, customer 1 pledges if and only if $v_{1} \geq \frac{p}{q_{i}-b q_{i}^{2}}$.

(a) From (8), as $\lim _{q_{i} \rightarrow 0^{+}} I=\infty$, there exists $\overline{q_{i}}(\geq 0)$ such that when $q_{i} \leq \overline{q_{i}}, \mathbb{P}($ improve $)=$ $\frac{\left(q_{i}+q_{u}\right)-b\left(q_{i}+q_{u}\right)^{2}-p}{\left(q_{i}+q_{u}\right)-b\left(q_{i}+q_{u}\right)^{2}}$ from (9). In this case, $\frac{\partial \mathbb{P}(\text { improve })}{\partial q_{i}}=\frac{p\left(1-2 b\left(q_{i}+q_{u}\right)\right)}{\left(\left(q_{i}+q_{u}\right)-b\left(q_{i}+q_{u}\right)^{2}\right)^{2}}>0$ if and only if $b\left(q_{i}+q_{u}\right)<$ 0.5. Also, as $\lim _{q_{i} \rightarrow \infty} I=-\infty$, there exists $\underline{q_{i}}(\in \mathbb{R} \cup\{+\infty\})$ such that when $q_{i}>\underline{q_{i}}, \mathbb{P}($ improve $)=0$. (b) When both $q_{f}=q_{i}$ and $q_{f}=q_{i}+q_{u}$, the probability of success is $\mathbb{P}($ success $)=\left(\frac{q_{f}-b q_{f}^{2}-p}{q_{f}-b q_{f}^{2}}\right)^{2}$. The first derivative of $\mathbb{P}($ success $)$ with respect to $q_{i}$ is $\frac{\partial \mathbb{P}(s u c c e s s)}{\partial q_{i}}=2\left(\frac{q_{i}-b q_{f}^{2}-p}{q_{f}-b q_{f}^{2}}\right)\left(\frac{p\left(1-2 b q_{f}\right)}{\left(q_{f}-b q_{f}^{2}\right)^{2}}\right)$. Thus, in both cases, when $b q_{f}<0.5, \mathbb{P}($ success $)$ is increasing in $q_{i}$; and when $b q_{f}>0.5, \mathbb{P}($ success $)$ is decreasing in $q_{i}$. From the proof of Proposition 3(a), when $q_{i}<\overline{q_{i}}, q_{f}=q_{i}+q_{u}$. Thus, when $q_{i}<q_{i}^{\prime}=\min \left\{\bar{q}_{i}, 0.5 / b-q_{u}\right\}, \mathbb{P}($ success $)$ is increasing in $q_{i}$. Also, since $q_{f}=q_{i}$ for $q_{i}>\underline{q_{i}}$, when $q_{i}>q_{i}^{\prime \prime}=\max \left\{\underline{q_{i}}, 0.5 / b\right\}, \mathbb{P}($ success $)$ is decreasing in $q_{i}$. 
Proof of Proposition 4. From (4), the creator's profit $\Pi$ with improvement under $q_{i}=q_{f}^{*}-q_{u}$ is larger than the creator's profit $\Pi$ without improvement under $q_{i}=q_{f}^{*}$. This is because in the former case, the creator saves $C_{i} q_{u}$. When there is an improvement, i.e., $I \geq 0$, the creator's profit

$$
\Pi\left(q_{i}\right)=\left(1-\frac{p}{\left(q_{i}+q_{u}\right)-b\left(q_{i}+q_{u}\right)^{2}}\right)^{2}\left(2 p-2 c\left(q_{i}+q_{u}\right)^{2}\right)-C_{i} q_{i} .
$$

Note that by Assumption $1, \Pi(0)>0$ and also note that $\Pi\left(q_{i}\right) \leq 0$ under any $q_{i}$ such that $q_{i}+$ $q_{u}-b\left(q_{i}+q_{u}\right)^{2}<p$ because no customer pledges under such $q_{i}$. Thus, without loss of optimality, we can restrict attention to $\left\{q_{i} \geq 0 \mid q_{i}+q_{u}-b\left(q_{i}+q_{u}\right)^{2} \geq p\right\}$, which is a compact set. In this region, $\Pi$ is continuous, so by Weierstrass Theorem, there exists a global maximizer $q_{i}^{*}$ of $\Pi$ in (10). Because $q_{i}^{*}$ is a maximizer, we have $\Pi\left(q_{i}^{*}\right) \geq \Pi(0)>0$. Furthermore, for any $q_{i} \geq 2 p / C_{i}$, we

have $\Pi\left(q_{i}\right) \leq 2 p-C_{i} q_{i} \leq 0$ since $\mathbb{P}($ success $)=\left(1-\frac{p}{\left(q_{i}+q_{u}\right)-b\left(q_{i}+q_{u}\right)^{2}}\right)^{2}<1$. Thus, we should have $q_{i}^{*}<2 p / C_{i}$. Because $\lim _{C_{i} \rightarrow \infty} 2 p / C_{i}=0, \lim _{C_{i} \rightarrow \infty} 0=0$, and $0 \leq q_{i}^{*}<2 p / C_{i}$, by Squeeze Theorem, $\lim _{C_{i} \rightarrow \infty} q_{i}^{*}=0$.

By Assumption 1, $\lim _{q_{i} \rightarrow 0} I>0$, and hence there exists $\underline{q_{i}}$ such that $I>0$ for any $q_{i}<\underline{q_{i}}$. Also, as $\lim _{C_{i} \rightarrow \infty} q_{i}^{*}=0$, there exists $\underline{C_{i}}$ such that $q_{i}^{*}<\underline{q_{i}}$ and hence $I>0$ for any $C_{i}>\underline{C_{i}}$. Therefore, it is optimal for the creator to make an improvement and set $q_{i}^{*}=q_{f}^{*}-q_{u}$ whenever $C_{i}>\underline{C_{i}}$.

\section{B. Additional Discussions}

\section{B.1. Details of LDA Model}

In this section, we discuss the details of the LDA method (Blei et al. 2003). The LDA method assumes that each document can be represented as a mixture of topics and each topic can be represented as a mixture of words. So, taking a corpus of documents as an input, the LDA method outputs the distribution of topics in each document and the distribution of words in each topic. The distribution of topics in each document is a vector of weights, where the weight of each topic represents how intensively the topic is used in the document. Similarly, the distribution of words in each topic represents the frequency of words. As product descriptions on campaign pages include explanation of product features, the LDA method is suitable for extracting topics related to these features from product descriptions (e.g., Tirunillai and Tellis 2014, Toubia et al. 2019).

To train the LDA model, we start with 43,536 initial and final descriptions of products in 21,768 campaigns. Following the standard practice (e.g., Tirunillai and Tellis 2014, Toubia et al. 2019), we first pre-process descriptions (e.g., remove stop words, remove descriptions that contain less than ten words and that are not written in English, and stem words). We then fit the LDA model on the corpus of the remaining 42,564 descriptions (from 21,380 campaigns, 196 of which only have a single description after pre-processing) using the standard hyperparameters of $\alpha=1$ and $\beta=0.01$ (e.g., Steyvers and Griffiths 2007, Toubia et al. 2019, Ghose et al. 2019), where $\alpha$ and 
HAIZE is a new type of navigation system designed for urban cyclists. It works like a magic compass that, instead of pointing north, points to the destination you set in our app. HAIZE leaves you free to choose your own route through the city. It also makes your ride safer by letting you keep your phone in your pocket. HAIZE can easily be attached to any bike and is small and built-to-last so that you can always bring it with you. Our companion app will be available for both Android- and iOS-based smartphones. HAIZE is easy to use. Simply attach it to your bike, set the destination in our companion app, put your phone away and let HAIZE guide you. Its simple LED-based display will point you in the right direction and let you know the distance to your destination. You can select between two different modes of navigation. The compass mode points you in the direction of your final destination and lets you explor along the way. The navigation mode sets a specific route and gives you turn-by-turn direction Check out the video of HAIZE in action: Check out this video of HAIZE and our app: HAIZ is stripped down to the essence, both the led-based display and the aluminium body combine simplicity with usability. The HAIZE led-display gives you all the information you need at glance; direction and distance. HAIZE lets you focus on the road and explore the city. If you are interested in additional details about your trip, you can always check the app after your ride. Here you will find stats about your trips and saved routes. The rubber band integrated in your pocket when leaving your bike on the street. The body of HAIZE has been created using machined anodized aluminium, making it both sturdy and stylish. The magnetometer tracks the direction to the destination The accelerometer and gyroscope are used to determine HAIZE position The light sensor is used to regulate the LED brightness to accommodate different lighting conditions The battery with $300 \mathrm{mAh}$ delivers 2 weeks of normal usage and can be easily recharged using a micro usb connection HAIZE is connected to our app via a low power bluetooth 4.0 connection As you can see there is a lot of technology packed into HAIZE

Existing $0.058^{*}$ "control" + $0.052 *$ "smart" + 0.037*"sensor" + 0.030 *"home" + 0.021 *"mode" + Topic $0.021 *$ "button" $+0.019^{*}$ "connect" $+0.017^{*}$ "set" $+0.017 *$ "remot" $+0.017^{*}$ "monitor"
HAIZE is minimalist navigation device for urban cyclists. It is designed focusing on high quality materials, style and simplicity. HAIZE works like a magic compass that, instead of pointing north, points to the destination you set in our app. HAIZE leaves you free to choose your own route through the city. It also makes your ride safer by letting you keep your phone in your pocket. If you feel like sticking to the main roads HAIZE also offers turn-by-turn navigation. WHY YOU NEED ONE? 2 navigation modes: "turn-by-turn mode" and "compas mode" Self-regulating LED display for perfect day and night-time visibility Sturdy and high-

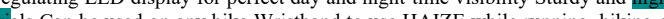
qualiy companion app, put your phone away and let HAIZE guide you. Its simple LED-based display will point you in the right direction and let you know the distance to your destination. You can select between two different modes of navigation. The compass mode points you in the direction of your final destination and lets you explore along the way. The navigation mode sets a specific route and gives you turn-by-turn directions. Check out the video of HAIZE in action: Check out this video of HAIZE and our app: HAIZE is stripped down to the essence, both the led-based display and the aluminium body combine simplicity with usability. HAIZE durable combination that stands out from the first moment. To know a direction you don't $t$ need o get distracted processing numbers or symbols on a screen. The HAIZE led-display gives you all the information you need at a glance; direction and distance in a simple and intuitive way. HAIZE lets you focus on the road and explore the city. If you are interested in additional details about your trip, you can check them in the app. There you will find stats about your trips and saved routes. HAIZE automatically regulates the brightness of the LEDs to work perfectly under any light condition. It will help you navigate the city no matter what time of the day? The elastic band integrated in the HAIZE body allows you to easily attach it on any bike and keep HAIZE comfortably in your pocket when leaving your bike on the street. And it always

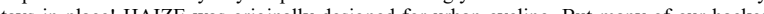
tays in place! HAIZE was originally designed for urban cycling. But many of our backer wanted to use it in other situations. That is why we decided to give every backer a wristband
to bring HAIZE along to any activity. Be it for hiking, running, or geo-caching. And of course to bring HAIZE along to any activity. Be it for hiking, running, or geo-caching. And of course
finding your way back to last years perfect mushroom spot. HAIZE will be able to guide you to the best spots while wandering freely. And you can be confident about getting back to the basecamp no matter how many turns you make. The HAIZE wristband is made from high quality silicone and fits perfectly around the aluminum case, allowing you to take HAIZE everywhere. The magnetometer tracks the direction to the destination The accelerometer and gyroscope are used to determine HAIZEs position The light sensor is used to regulate the LED brightness to accommodate different lighting conditions The battery with $300 \mathrm{mAh}$ delivers 2 we connection HAIZE is connected to our app via a low power bluetooth 4.0 connection As you can see there is a lot of technology packed into HAIZE...

\begin{tabular}{|c|c|}
\hline $\begin{array}{c}\text { Existing } \\
\text { Topic }\end{array}$ & $\begin{array}{l}0.058^{*} \text { "control" }+0.052 * \text { "smart" }+0.037 * \text { "sensor" }+0.03 * \text { "home" }+0.021 * \text { "mode" }+ \\
0.021 * \text { "button" }+0.019 * \text { "connect" }+0.017 * \text { "set" }+0.017 * \text { remot" }+0.017 * \text { monitor" }\end{array}$ \\
\hline Added & 0.059*"materi" + $0.032^{*}$ "weight" + $0.032 *$ high" + $0.030^{*}$ "durabl" + $0.027 *$ "surfac" + \\
\hline
\end{tabular}

(a) Excerpt from the initial description where words correspond-(b) Excerpt from the final description where words corresponding to an existing topic are highlighted.

ing to an existing topic and an added topic are highlighted.

Figure B1 Initial and final descriptions of the product HAIZE with examples of an "existing" topic that is available in the initial description and an "added" topic that is added to the final description. Tables below excerpts illustrate the most relevant ten words with their weights in these topics.

$\beta$ are parameters of the prior Dirichlet distributions of topics in documents and words in topics, respectively (Blei et al. 2003). Following the rule of $\alpha=50 / T$, where $T$ is the number of topics, (e.g., Steyvers and Griffiths 2007, Tirunillai and Tellis 2014), we set the number of topics to 50. From the trained LDA model, we obtain weights of words in each of 50 topics and weights of topics in each of 42,564 descriptions; all weights are positive. See Figure B1 for an example. 


\section{Online Appendix}

\section{EC.1. Cost of Commenting}

In this section, we consider the case where customer 1 incurs cost of $d(>0)$ when she makes a comment. Suppose that condition (1) holds so that customer 1 anticipates an improvement. Then, customer 1 decides whether to make a comment or not by comparing $U_{1}^{C}$ when she makes a comment and $U_{1}^{N C}$ when she does not make a comment, where

$$
U_{1}^{C}=\left(\frac{q_{i}+q_{u}-p}{q_{i}+q_{u}}\right)\left(v_{1}\left(q_{i}+q_{u}\right)-p\right)-d \text { and } U_{1}^{N C}=\left(\frac{q_{i}-p}{q_{i}}\right)\left(v_{1} q_{i}-p\right) .
$$

Thus, customer 1 makes a comment if and only if $U_{1}^{C} \geq U_{1}^{N C}$, i.e., $v_{1} \geq \frac{p^{2}}{q_{i}\left(q_{i}+q_{u}\right)}+\frac{d}{q_{u}}$. Suppose that $v_{1} \geq \frac{p^{2}}{q_{i}\left(q_{i}+q_{u}\right)}+\frac{d}{q_{u}}$. Then, in the first stage, customer 1 decides whether to pledge or not by comparing $U_{1}^{P}$ when she pledges and $U_{1}^{N P}$ when she does not pledge, where

$$
U_{1}^{P}=\left(\frac{q_{i}+q_{u}-p}{q_{i}+q_{u}}\right)\left(v_{1}\left(q_{i}+q_{u}\right)-p\right)-d \text { and } U_{1}^{N P}=0 .
$$

Thus, customer 1 pledges if $U_{1}^{P} \geq U_{1}^{N P}$, i.e., $v_{1} \geq \frac{p}{q_{i}+q_{u}}+\frac{d}{q_{i}+q_{u}-p}$, and hence customer 1 pledges and makes a comment if $v_{1} \geq \max \left\{\frac{p^{2}}{q_{i}\left(q_{i}+q_{u}\right)}+\frac{d}{q_{u}}, \frac{p}{q_{i}+q_{u}}+\frac{d}{q_{i}+q_{u}-p}\right\}$. Next, suppose that $v_{1}<\frac{p^{2}}{q_{i}\left(q_{i}+q_{u}\right)}+$ $\frac{d}{q_{u}}$. Then, customer 1 decides whether to pledge or not by comparing $U_{1}^{P}=\left(\frac{q_{i}-p}{q_{i}}\right)\left(v_{1} q_{i}-p\right)$ and $U_{1}^{N P}=0$. Thus, customer 1 pledges if and only if $v_{1} \geq \frac{p}{q_{i}}$. Therefore, customer 1 pledges but does make a comment if $\frac{p}{q_{i}} \leq v_{1} \leq \frac{p^{2}}{q_{i}\left(q_{i}+q_{u}\right)}+\frac{d}{q_{u}}$. Finally, suppose that condition (1) is violated. Then, customer 1 pledges if and only if $v_{1} \geq \frac{p}{q_{i}}$. We characterize all possible outcomes of this model in the following lemma.

LEMMA EC.A1. (a) Suppose that $\frac{p^{2}}{q_{i}\left(q_{i}+q_{u}\right)}-c\left(2 q_{i}+q_{u}-p\right) \geq 0$.

(i) Suppose that $1 \geq \frac{p}{q_{i}+q_{u}}+\frac{d}{q_{i}+q_{u}-p} \geq \frac{p^{2}}{q_{i}\left(q_{i}+q_{u}\right)}+\frac{d}{q_{u}}$.

$$
\mathbb{P}(\text { success })=\left(1-\frac{p}{q_{i}+q_{u}}-\frac{d}{q_{i}+q_{u}-p}\right)\left(1-\frac{p}{q_{i}+q_{u}}\right) .
$$

(ii) Suppose that $\frac{p}{q_{i}+q_{u}}+\frac{d}{q_{i}+q_{u}-p}<\frac{p^{2}}{q_{i}\left(q_{i}+q_{u}\right)}+\frac{d}{q_{u}} \leq 1$.

$$
\mathbb{P}(\text { success })=\left(1-\frac{p^{2}}{q_{i}\left(q_{i}+q_{u}\right)}-\frac{d}{q_{u}}\right)\left(1-\frac{p}{q_{i}+q_{u}}\right)+\left(\frac{p^{2}}{q_{i}\left(q_{i}+q_{u}\right)}+\frac{d}{q_{u}}-\frac{p}{q_{i}}\right)\left(1-\frac{p}{q_{i}}\right)
$$

(iii) Suppose that $\frac{p}{q_{i}+q_{u}}+\frac{d}{q_{i}+q_{u}-p} \leq 1<\frac{p^{2}}{q_{i}\left(q_{i}+q_{u}\right)}+\frac{d}{q_{u}}$.

$$
\mathbb{P}(\text { success })=\left(1-\frac{p}{q_{i}}\right)^{2} .
$$

(b) Suppose that $\frac{p^{2}}{q_{i}\left(q_{i}+q_{u}\right)}-c\left(2 q_{i}+q_{u}-p\right)<0$.

$$
\mathbb{P}(\text { success })=\left(1-\frac{p}{q_{i}}\right)^{2} .
$$

Proof of Lemma EC.A1. Overall, there are four possible cases: 
Case (a). Suppose that $\frac{p^{2}}{q_{i}\left(q_{i}+q_{u}\right)}-c\left(2 q_{i}+q_{u}-p\right) \geq 0$ such that the creator is willing to improve the product further if customer 1 makes a comment.

Case (a-i). Suppose that $1 \geq \frac{p}{q_{i}+q_{u}}+\frac{d}{q_{i}+q_{u}-p} \geq \frac{p^{2}}{q_{i}\left(q_{i}+q_{u}\right)}+\frac{d}{q_{u}}$ such that customer 1 makes a comment whenever she pledges. (Note that when $\frac{p}{q_{i}+q_{u}}+\frac{d}{q_{i}+q_{u}-p}>1$, customer 1 never pledges.) In this case, the creator's expected profit is as follows:

$$
\Pi=\left(1-\frac{p}{q_{i}+q_{u}}-\frac{d}{q_{i}+q_{u}-p}\right)\left(1-\frac{p}{q_{i}+q_{u}}\right)\left(2 p-2 c\left(q_{i}+q_{u}\right)^{2}\right)-C_{i} q_{i} .
$$

So, in this case probability of campaign success is as in (EC.1).

Case (a-ii). Suppose that $\frac{p}{q_{i}+q_{u}}+\frac{d}{q_{i}+q_{u}-p}<\frac{p^{2}}{q_{i}\left(q_{i}+q_{u}\right)}+\frac{d}{q_{u}} \leq 1$ such that customer 1 may not make a comment although she pledges. In this case, the creator's expected profit is as follows:

$$
\begin{aligned}
\Pi= & \left(1-\frac{p^{2}}{q_{i}\left(q_{i}+q_{u}\right)}-\frac{d}{q_{u}}\right)\left(1-\frac{p}{q_{i}+q_{u}}\right)\left(2 p-2 c\left(q_{i}+q_{u}\right)^{2}\right) \\
& +\left(\frac{p^{2}}{q_{i}\left(q_{i}+q_{u}\right)}+\frac{d}{q_{u}}-\frac{p}{q_{i}}\right)\left(1-\frac{p}{q_{i}}\right)\left(2 p-2 c q_{i}^{2}\right)-C_{i} q_{i} .
\end{aligned}
$$

So, in this case probability of campaign success is as in (EC.2).

Case (a-iii). Suppose that $\frac{p}{q_{i}+q_{u}}+\frac{d}{q_{i}+q_{u}-p} \leq 1<\frac{p^{2}}{q_{i}\left(q_{i}+q_{u}\right)}+\frac{d}{q_{u}}$ such that customer 1 never makes a comment although she may pledge. In this case, the creator's expected profit is as follows:

$$
\Pi=\mathbb{P}\left(v_{1} \geq \frac{p}{q_{i}}\right) \cdot \mathbb{P}\left(v_{2} \geq \frac{p}{q_{i}}\right)\left(2 p-2 c q_{i}^{2}\right)-C_{i} q_{i}=\left(1-\frac{p}{q_{i}}\right)^{2}\left(2 p-2 c q_{i}^{2}\right)-C_{i} q_{i} .
$$

So, in this case probability of campaign success is is as in (EC.3).

Case (b). Suppose that $\frac{p^{2}}{q_{i}\left(q_{i}+q_{u}\right)}-c\left(2 q_{i}+q_{u}-p\right)<0$ such that the creator is not willing to improve the product further. In this case, the creator's expected profit is as follows:

$$
\Pi=\left(1-\frac{p}{q_{i}}\right)^{2}\left(2 p-2 c q_{i}^{2}\right)-C_{i} q_{i} .
$$

So, in this case probability of campaign success is as in (EC.4).

We numerically analyze these cases according to the setting where we select $p$ from Uniform $(0,1)$, $c$ from Uniform(0,0.01), $q_{u}$ from Uniform(0,0.5), and cost of commenting $d$ from Uniform(0,0.01). Taking the average of randomly generated 10,000 instances, we show that our theoretical predictions hold. 


\section{EC.2. Robustness Checks}

In this section, we provide results of probit and IV models for robustness checks that we discuss in $\S 3.4$.

Table EC.1 Spline regressions for second-stage estimations in IV models.

\begin{tabular}{|c|c|c|}
\hline & $\frac{\text { Second Stage of IV Model } 1}{\text { Product improvement }}$ & $\frac{\text { Second Stage of IV Model } 2}{\text { Campaign success }}$ \\
\hline Initial enhancement level $(\leq 30)$ & $\begin{array}{c}0.053 * * * \\
(0.008)\end{array}$ & $\begin{array}{c}0.073^{* * *} \\
(0.008)\end{array}$ \\
\hline Initial enhancement level (> 30) & $\begin{array}{c}-0.115^{* * *} \\
(0.029)\end{array}$ & $\begin{array}{c}-0.056 * * \\
(0.023)\end{array}$ \\
\hline Residuals & $\begin{array}{l}-0.036 * * * \\
(0.008)\end{array}$ & $\begin{array}{c}-0.046^{* * *} \\
(0.009)\end{array}$ \\
\hline Competition & $\begin{array}{l}-0.572 \\
(0.365)\end{array}$ & $\begin{array}{c}-1.095^{* * *} \\
(0.336)\end{array}$ \\
\hline Technology & $\begin{array}{c}0.006 \\
(0.024)\end{array}$ & $\begin{array}{l}-0.041 \\
(0.025)\end{array}$ \\
\hline Goal (ln) & $\begin{array}{l}-0.022^{* * *} \\
(0.008)\end{array}$ & $\begin{array}{l}-0.344 * * * \\
(0.009)\end{array}$ \\
\hline Duration & $\begin{array}{c}0.003 * * * \\
(0.001)\end{array}$ & $\begin{array}{l}-0.001 \\
(0.001)\end{array}$ \\
\hline Videos & $\begin{array}{l}-0.007 \\
(0.014)\end{array}$ & $\begin{array}{c}-0.035^{* * *} \\
(0.013)\end{array}$ \\
\hline Pictures & $\begin{array}{c}0.003 \\
(0.002)\end{array}$ & $\begin{array}{c}0.021 * * * \\
(0.003)\end{array}$ \\
\hline Risk-section length & $\begin{array}{l}-0.000 \\
(0.000)\end{array}$ & $\begin{array}{c}-0.000^{* *} \\
(0.000)\end{array}$ \\
\hline Pledge price & $\begin{array}{c}0.000 \\
(0.000)\end{array}$ & $\begin{array}{c}0.000 * * * \\
(0.000)\end{array}$ \\
\hline Delivery time & $\begin{array}{c}0.001 \\
(0.002)\end{array}$ & $\begin{array}{c}-0.006^{* *} \\
(0.003)\end{array}$ \\
\hline Creator experience & $\begin{array}{l}0.021^{*} \\
(0.012)\end{array}$ & $\begin{array}{c}0.268 * * * \\
(0.025)\end{array}$ \\
\hline Individual & $\begin{array}{l}-0.148 * * * \\
(0.024)\end{array}$ & $\begin{array}{c}-0.360 * * * \\
(0.021)\end{array}$ \\
\hline Constant & $\begin{array}{l}-0.929 * * * \\
(0.083)\end{array}$ & $\begin{array}{l}2.292 * * * \\
(0.088)\end{array}$ \\
\hline Observations & 18,173 & 18,173 \\
\hline
\end{tabular}

Nonparametric bootstrap standard errors (100 replications) in parentheses.

$* * * p<0.01, * * p<0.05, * p<0.1$ 
Table EC.2 Equal time periods before and after IV.

\begin{tabular}{|c|c|c|c|c|c|}
\hline & $\begin{array}{c}\text { Probit Model 1 } \\
\text { Product improvement }\end{array}$ & $\begin{array}{r}\text { Probit Model 2 } \\
\text { Campaign success }\end{array}$ & $\begin{array}{l}\frac{\text { First Stage of IV Models }}{1 \text { and } 2} \\
\text { Initial enhancement level }\end{array}$ & $\begin{array}{c}\frac{\text { Second Stage of IV }}{\text { Model } 1} \\
\text { Product improvement }\end{array}$ & $\begin{array}{l}\frac{\text { Second Stage of IV }}{\text { Model } 2} \\
\text { Campaign success }\end{array}$ \\
\hline Initial enhancement level & $\begin{array}{c}.071^{* * *} \\
(.005)\end{array}$ & $\begin{array}{c}.089 * * * \\
(.005)\end{array}$ & & $\begin{array}{c}.086^{* * *} \\
(.017)\end{array}$ & $\begin{array}{c}.138^{* * *} \\
(.016)\end{array}$ \\
\hline $\begin{array}{l}\text { Initial enhancement level } \times \\
\text { Initial enhancement level }\end{array}$ & $-.002 * * *$ & $-.002 * * *$ & & $-.002 * * *$ & $-.003 * * *$ \\
\hline Competition & $\begin{array}{l}(.000) \\
-1.569 * * * \\
(.322)\end{array}$ & $\begin{array}{l}(.000) \\
-2.472 * * * \\
(.314)\end{array}$ & $\begin{array}{c}-9.545^{* * *} \\
(2.015)\end{array}$ & $\begin{array}{c}(.000) \\
-1.22 * * \\
(.597)\end{array}$ & $\begin{array}{c}(.000) \\
-1.044^{*} \\
(.57)\end{array}$ \\
\hline Category: Technology & $\begin{array}{c}.075^{* * *} \\
(.024)\end{array}$ & $\begin{array}{l}.003 \\
(.026)\end{array}$ & $\begin{array}{c}1.289^{* * *} \\
(.133)\end{array}$ & $\begin{array}{l}.06^{*} \\
(.036)\end{array}$ & $\begin{array}{l}-.058 \\
(.037)\end{array}$ \\
\hline Goal $(\ln )$ & $\begin{array}{l}-.01 \\
(.009)\end{array}$ & $\begin{array}{c}-.325 * * * \\
(.011)\end{array}$ & $\begin{array}{c}.691 * * * \\
(.043)\end{array}$ & $\begin{array}{l}-.018 \\
(.014)\end{array}$ & $\begin{array}{c}-.357 * * * \\
(.016)\end{array}$ \\
\hline Duration & $\begin{array}{c}.004^{* * * *} \\
(.001)\end{array}$ & $\begin{array}{l}-.002^{*} \\
(.001)\end{array}$ & $\begin{array}{c}-.022 * * * \\
(.006)\end{array}$ & $\begin{array}{c}.004^{* * * *} \\
(.001)\end{array}$ & $\begin{array}{l}-.001 \\
(.001)\end{array}$ \\
\hline Videos & $\begin{array}{l}.025 \\
(.016)\end{array}$ & $\begin{array}{l}-.028 \\
(.019)\end{array}$ & $\begin{array}{l}.705^{* * *} \\
(.143)\end{array}$ & $\begin{array}{l}.016 \\
(.02)\end{array}$ & $\begin{array}{c}-.06 * * * \\
(.023)\end{array}$ \\
\hline Pictures & $\begin{array}{c}.015^{* * *} \\
(.001)\end{array}$ & $\begin{array}{c}.032 * * * \\
(.002)\end{array}$ & $\begin{array}{c}.328^{* * *} \\
(.009)\end{array}$ & $\begin{array}{l}.011^{* *} \\
(.005)\end{array}$ & $\begin{array}{c}.017^{* * *} \\
(.006)\end{array}$ \\
\hline Risk-section length & $\begin{array}{c}0^{* * *} \\
(.000)\end{array}$ & $\begin{array}{c}0^{* *} \\
(.000)\end{array}$ & $\begin{array}{c}.013^{* * *} \\
(.001)\end{array}$ & $\begin{array}{c}0 \\
(.000)\end{array}$ & $\begin{array}{c}0^{*} \\
(.000)\end{array}$ \\
\hline Pledge price & $\begin{array}{c}0 \\
(.000)\end{array}$ & $\begin{array}{l}0 * * * \\
(.000)\end{array}$ & $\begin{array}{c}0 \\
(.000)\end{array}$ & $\begin{array}{c}0 \\
(.000)\end{array}$ & $\begin{array}{l}0 * * * \\
(.000)\end{array}$ \\
\hline Delivery time & $\begin{array}{l}.003 \\
(.003)\end{array}$ & $\begin{array}{l}-.002 \\
(.003)\end{array}$ & $\begin{array}{l}.013 \\
(.012)\end{array}$ & $\begin{array}{l}.003 \\
(.003)\end{array}$ & $\begin{array}{l}-.002 \\
(.003)\end{array}$ \\
\hline Creator experience & $\begin{array}{l}.058^{* *} \\
(.026)\end{array}$ & $\begin{array}{c}.329^{* * * *} \\
(.033)\end{array}$ & $\begin{array}{c}.322 * * * \\
(.12)\end{array}$ & $\begin{array}{l}.055^{* *} \\
(.026)\end{array}$ & $\begin{array}{c}.319^{* * *} \\
(.034)\end{array}$ \\
\hline Individual & $\begin{array}{c}-.186^{* * * *} \\
(.032)\end{array}$ & $\begin{array}{c}-.388 * * * \\
(.029)\end{array}$ & $\begin{array}{l}-.093 \\
(.129)\end{array}$ & $\begin{array}{c}-.185^{* * *} \\
(.032)\end{array}$ & $\begin{array}{c}-.387^{* * *} \\
(.029)\end{array}$ \\
\hline Before relaxation of rules & & & $\begin{array}{c}2.758^{* * * *} \\
(.209)\end{array}$ & & \\
\hline Residuals & & & & $\begin{array}{l}-.012 \\
(.016)\end{array}$ & $\begin{array}{c}-.046^{* * *} \\
(.016)\end{array}$ \\
\hline Residuals $\times$ Residuals & & & & $\begin{array}{c}0^{*} \\
(.000)\end{array}$ & $\begin{array}{l}.001 * * \\
(.000)\end{array}$ \\
\hline Constant & $\begin{array}{c}-.959 * * * \\
(.106)\end{array}$ & $\begin{array}{c}2.32^{* * * *} \\
(.108)\end{array}$ & $\begin{array}{c}-1.838^{* * *} \\
(.49)\end{array}$ & $\begin{array}{l}-1 * * * \\
(.109)\end{array}$ & $\begin{array}{c}2.19^{* * * *} \\
(.114)\end{array}$ \\
\hline $\begin{array}{l}\text { Observations } \\
\text { pseudo } R^{2}\end{array}$ & $\begin{array}{c}11764 \\
.06\end{array}$ & $\begin{array}{c}11764 \\
.187\end{array}$ & $\begin{array}{c}11764 \\
.416\end{array}$ & $\begin{array}{c}11764 \\
.061\end{array}$ & $\begin{array}{c}11764 \\
.189\end{array}$ \\
\hline
\end{tabular}

Table EC.3 Campaigns where final enhancement level is greater than or equal to initial enhancement level.

\begin{tabular}{|c|c|c|c|c|c|}
\hline & $\begin{array}{c}\text { Probit Model 1 } \\
\text { Product improvement }\end{array}$ & $\begin{array}{c}\text { Probit Model } 2 \\
\text { Campaign success }\end{array}$ & $\begin{array}{l}\text { First Stage of IV Models } \\
\frac{1 \text { and } 2}{\text { Initial enhancement level }}\end{array}$ & $\begin{array}{c}\frac{\text { Second Stage of IV }}{\text { Model } 1} \\
\text { Product improvement }\end{array}$ & $\begin{array}{l}\frac{\text { Second Stage of IV }}{\text { Model } 2} \\
\text { Campaign success }\end{array}$ \\
\hline Initial enhancement level & $\begin{array}{c}.078^{* * *} \\
(.004)\end{array}$ & $\begin{array}{l}.09 * * * \\
(.004)\end{array}$ & & $\begin{array}{c}.106^{* * *} \\
(.009)\end{array}$ & $\begin{array}{c}.13 * * * \\
(.01)\end{array}$ \\
\hline $\begin{array}{l}\text { Initial enhancement level } \times \\
\text { Initial enhancement level }\end{array}$ & $-.002 * * *$ & $-.002 * * *$ & & $-.002 * * *$ & $-.003 * * *$ \\
\hline & $(.000)$ & $(.000)$ & & $(.000)$ & $(.000)$ \\
\hline Competition & $\begin{array}{c}-1.294 * * * \\
(.24)\end{array}$ & $\begin{array}{c}-2.117 * * * \\
(.296)\end{array}$ & $\begin{array}{l}-1.574 \\
(1.33)\end{array}$ & $\begin{array}{c}-.676^{* *} \\
(.274)\end{array}$ & $\begin{array}{c}-1.284 * * * \\
(.373)\end{array}$ \\
\hline Category: Technology & $\begin{array}{l}.059^{* *} \\
(.025)\end{array}$ & $\begin{array}{l}.035 \\
(.026)\end{array}$ & $\begin{array}{c}.965 * * * \\
(.095)\end{array}$ & $\begin{array}{l}.03 \\
(.026)\end{array}$ & $\begin{array}{l}-.003 \\
(.029)\end{array}$ \\
\hline Goal (ln) & $\begin{array}{l}-.006 \\
(.007)\end{array}$ & $\begin{array}{c}-.334 * * * \\
(.008)\end{array}$ & $\begin{array}{c}.571 * * * \\
(.032)\end{array}$ & $\begin{array}{c}-.022 * * \\
(.009)\end{array}$ & $\begin{array}{c}-.356^{* * *} \\
(.009)\end{array}$ \\
\hline Duration & $\begin{array}{c}.003 * * * \\
(.001)\end{array}$ & $\begin{array}{c}-.002 * * \\
(.001)\end{array}$ & $\begin{array}{c}-.016^{* * *} \\
(.004)\end{array}$ & $\begin{array}{c}.004^{* * *} \\
(.001)\end{array}$ & $\begin{array}{c}-.002 \\
(.001)\end{array}$ \\
\hline Videos & $\begin{array}{l}.028 * * \\
(.014)\end{array}$ & $\begin{array}{l}-.007 \\
(.015)\end{array}$ & $\begin{array}{c}.681 * * * \\
(.101)\end{array}$ & $\begin{array}{l}.009 \\
(.015)\end{array}$ & $\begin{array}{c}-.032 * * \\
(.015)\end{array}$ \\
\hline Pictures & $\begin{array}{c}.015^{* * *} \\
(.001)\end{array}$ & $\begin{array}{c}.035 * * * \\
(.001)\end{array}$ & $\begin{array}{c}.298 * * * \\
(.006)\end{array}$ & $\begin{array}{l}.006 * * \\
(.003)\end{array}$ & $\begin{array}{c}.024 * * * \\
(.003)\end{array}$ \\
\hline Risk-section length & $\begin{array}{l}0^{* * * *} \\
(.000)\end{array}$ & $\begin{array}{l}0^{* * *} \\
(.000)\end{array}$ & $\begin{array}{c}.015^{* * *} \\
(.001)\end{array}$ & $\begin{array}{c}0 \\
(.000)\end{array}$ & $\begin{array}{c}0 \\
(.000)\end{array}$ \\
\hline Pledge price & $\begin{array}{c}0 \\
(.000)\end{array}$ & $\begin{array}{l}0^{* * *} \\
(.000)\end{array}$ & $\begin{array}{c}0 \\
(.000)\end{array}$ & $\begin{array}{c}0 \\
(.000)\end{array}$ & $\begin{array}{c}0^{* * *} \\
(.000)\end{array}$ \\
\hline Delivery time & $\begin{array}{l}.003 \\
(.002)\end{array}$ & $\begin{array}{c}-.005^{* *} \\
(.002)\end{array}$ & $\begin{array}{l}.011 \\
(.009)\end{array}$ & $\begin{array}{l}.002 \\
(.002)\end{array}$ & $\begin{array}{c}-.005 * * \\
(.002)\end{array}$ \\
\hline Creator experience & $\begin{array}{l}.017 \\
(.013)\end{array}$ & $\begin{array}{c}.255^{* * *} \\
(.026)\end{array}$ & $\begin{array}{c}.221 * * * \\
(.063)\end{array}$ & $\begin{array}{c}.015 \\
(.013)\end{array}$ & $\begin{array}{c}.254^{* * * *} \\
(.026)\end{array}$ \\
\hline Individual & $\begin{array}{l}-.145 * * * \\
(.026)\end{array}$ & $\begin{array}{c}-.34 * * * \\
(.029)\end{array}$ & $\begin{array}{l}-.009 \\
(.098)\end{array}$ & $\begin{array}{l}-.146 * * * \\
(.027)\end{array}$ & $\begin{array}{c}-.343 * * * \\
(.028)\end{array}$ \\
\hline Before relaxation of rules & & & $\begin{array}{c}3.606^{* * *} * \\
(.145)\end{array}$ & & \\
\hline Residuals & & & & $\begin{array}{c}-.029 * * * \\
(.008)\end{array}$ & $\begin{array}{c}-.039 * * * \\
(.01)\end{array}$ \\
\hline Residuals $\times$ Residuals & & & & $\begin{array}{c}0 \\
(.000)\end{array}$ & $\begin{array}{c}0^{*} \\
(.000)\end{array}$ \\
\hline Constant & $\begin{array}{c}-1.066^{* * *} \\
(.07)\end{array}$ & $\begin{array}{c}2.257 * * * \\
(.079)\end{array}$ & $\begin{array}{c}-2.679 * * * \\
(.369)\end{array}$ & $\begin{array}{c}-1.107 * * * \\
(.073)\end{array}$ & $\begin{array}{c}2.203^{* * * *} \\
(.08)\end{array}$ \\
\hline $\begin{array}{l}\text { Observations } \\
\text { pseudo } R^{2}\end{array}$ & $\begin{array}{c}17005 \\
.074 \\
\end{array}$ & $\begin{array}{c}17005 \\
.211 \\
\end{array}$ & $\begin{array}{c}17005 \\
.398 \\
\end{array}$ & $\begin{array}{c}17005 \\
.074 \\
\end{array}$ & $\begin{array}{c}17005 \\
.212 \\
\end{array}$ \\
\hline
\end{tabular}

Nonparametric bootstrap standard errors (100 replications) in parentheses.

${ }_{* * *} p<.01,{ }^{* *} p<.05, * p<.1$ 
Table EC.4 Treating cancelled campaigns as failed campaigns.

\begin{tabular}{|c|c|c|c|c|c|}
\hline & $\begin{array}{c}\text { Probit Model 1 } \\
\text { Product improvement }\end{array}$ & $\begin{array}{r}\text { Probit Model } 2 \\
\text { Campaign success }\end{array}$ & $\begin{array}{l}\frac{\text { First Stage of IV Models }}{\underline{1 \text { and } 2}} \\
\text { Initial enhancement level }\end{array}$ & $\begin{array}{c}\frac{\text { Second Stage of IV }}{\text { Model } 1} \\
\text { Product improvement }\end{array}$ & $\begin{array}{l}\frac{\text { Second Stage of IV }}{\text { Model } 2} \\
\text { Campaign success }\end{array}$ \\
\hline Initial enhancement level & $\begin{array}{l}.07 * * * \\
(.004)\end{array}$ & $\begin{array}{c}.086^{* * *} \\
(.004)\end{array}$ & & $\begin{array}{c}.103^{* * *} \\
(.007)\end{array}$ & $\begin{array}{c}.123 * * * \\
(.008)\end{array}$ \\
\hline $\begin{array}{l}\text { Initial enhancement level } \times \\
\text { Initial enhancement level }\end{array}$ & $-.002 * * *$ & $-.002 * * *$ & & $-.002 * * *$ & $-.002 * * *$ \\
\hline & $(.000)$ & $(.000)$ & & $(.000)$ & $(.000)$ \\
\hline Competition & $\begin{array}{c}-.898^{* * * *} \\
(.238)\end{array}$ & $\begin{array}{c}-1.763 * * * \\
(.253)\end{array}$ & $\begin{array}{l}-1.678 \\
(1.118)\end{array}$ & $\begin{array}{c}-.386 \\
(.241)\end{array}$ & $\begin{array}{c}-1.046 * * * \\
(.291)\end{array}$ \\
\hline Category: Technology & $\begin{array}{l}.054^{* *} \\
(.021)\end{array}$ & $\begin{array}{c}.027 \\
(.019)\end{array}$ & $\begin{array}{c}1.031^{* * *} \\
(.092)\end{array}$ & $\begin{array}{l}.026 \\
(.022)\end{array}$ & $\begin{array}{l}-.011 \\
(.02)\end{array}$ \\
\hline Goal $(\ln )$ & $\begin{array}{l}-.005 \\
(.007)\end{array}$ & $\begin{array}{c}-.329 * * * \\
(.008)\end{array}$ & $\begin{array}{l}.6 * * * \\
(.032)\end{array}$ & $\begin{array}{l}-.02 * * \\
(.008)\end{array}$ & $\begin{array}{c}-.351 * * * \\
(.008)\end{array}$ \\
\hline Duration & $\begin{array}{c}.003 * * * \\
(.001)\end{array}$ & $\begin{array}{c}-.003 * * * \\
(.001)\end{array}$ & $\begin{array}{c}-.014^{* * *} \\
(.005)\end{array}$ & $\begin{array}{c}.003^{* * *} \\
(.001)\end{array}$ & $\begin{array}{c}-.003 * * * \\
(.001)\end{array}$ \\
\hline Videos & $\begin{array}{l}.018^{*} \\
(.01)\end{array}$ & $\begin{array}{c}-.018 \\
(.011)\end{array}$ & $\begin{array}{c}.723 * * * \\
(.084)\end{array}$ & $\begin{array}{c}-.002 \\
(.011)\end{array}$ & $\begin{array}{c}-.043 * * * \\
(.013)\end{array}$ \\
\hline Pictures & $\begin{array}{c}.009 * * * \\
(.001)\end{array}$ & $\begin{array}{c}.027 * * * \\
(.001)\end{array}$ & $\begin{array}{c}.287^{* * *} \\
(.006)\end{array}$ & $\begin{array}{l}.001 \\
(.002)\end{array}$ & $\begin{array}{c}.016^{* * * *} \\
(.003)\end{array}$ \\
\hline Risk-section length & $\begin{array}{l}0^{* * *} \\
(.000)\end{array}$ & $\begin{array}{l}0^{* * *} \\
(.000)\end{array}$ & $\begin{array}{c}.016^{* * *} \\
(.001)\end{array}$ & $\begin{array}{c}0 * * \\
(.000)\end{array}$ & $\begin{array}{l}0 * * \\
(.000)\end{array}$ \\
\hline Pledge price & $\begin{array}{c}0 \\
(.000)\end{array}$ & $\begin{array}{c}0^{* * *} \\
(.000)\end{array}$ & $\begin{array}{c}0 \\
(.000)\end{array}$ & $\begin{array}{c}0 \\
(.000)\end{array}$ & $\begin{array}{c}0 * * * \\
(.000)\end{array}$ \\
\hline Delivery time & $\begin{array}{l}.001 \\
(.002)\end{array}$ & $\begin{array}{c}-.005^{* *} \\
(.002)\end{array}$ & $\begin{array}{l}.007 \\
(.009)\end{array}$ & $\begin{array}{l}.001 \\
(.002)\end{array}$ & $\begin{array}{c}-.005 * * \\
(.002)\end{array}$ \\
\hline Creator experience & $\begin{array}{l}.016 \\
(.01)\end{array}$ & $\begin{array}{c}.154^{* * * *} \\
(.016)\end{array}$ & $\begin{array}{c}.177 * * * \\
(.042)\end{array}$ & $\begin{array}{l}.014 \\
(.01)\end{array}$ & $\begin{array}{c}.153^{* * *} \\
(.017)\end{array}$ \\
\hline Individual & $\begin{array}{c}-.152 * * * \\
(.023)\end{array}$ & $\begin{array}{c}-.336 * * * \\
(.024)\end{array}$ & $\begin{array}{c}-.072 \\
(.101)\end{array}$ & $\begin{array}{c}-.153 * * * \\
(.023)\end{array}$ & $\begin{array}{c}-.337 * * * \\
(.024)\end{array}$ \\
\hline Before relaxation of rules & & & $\begin{array}{c}3.562 * * * \\
(.134)\end{array}$ & & \\
\hline Residuals & & & & $\begin{array}{c}-.028 * * * \\
(.007)\end{array}$ & $\begin{array}{c}-.037 * * * \\
(.008)\end{array}$ \\
\hline Residuals $\times$ Residuals & & & & $\begin{array}{c}.001^{* * *} \\
(.000)\end{array}$ & $\begin{array}{c}0^{*} \\
(.000)\end{array}$ \\
\hline Constant & $\begin{array}{c}-1.086^{* * *} \\
(.078)\end{array}$ & $\begin{array}{c}2.218^{* * * *} \\
(.085)\end{array}$ & $\begin{array}{c}-2.738 * * * \\
(.366)\end{array}$ & $\begin{array}{c}-1.139 * * * \\
(.075)\end{array}$ & $\begin{array}{c}2.167^{* * * *} \\
(.087)\end{array}$ \\
\hline $\begin{array}{l}\text { Observations } \\
\text { pseudo } R^{2}\end{array}$ & $\begin{array}{c}21184 \\
.049 \\
\end{array}$ & $\begin{array}{c}21184 \\
.177 \\
\end{array}$ & $\begin{array}{c}21184 \\
.399 \\
\end{array}$ & $\begin{array}{c}21184 \\
.051 \\
\end{array}$ & $\begin{array}{c}21184 \\
.178 \\
\end{array}$ \\
\hline
\end{tabular}

Table EC.5 When the number of topics is set to 40 in LDA Model.

\begin{tabular}{|c|c|c|c|c|c|}
\hline & $\begin{array}{c}\text { Probit Model 1 } \\
\text { Product improvement }\end{array}$ & $\begin{array}{c}\text { Probit Model 2 } \\
\text { Campaign success }\end{array}$ & $\begin{array}{l}\frac{\text { First Stage of IV Models }}{\frac{1 \text { and } 2}{\text { Initial enhancement level }}} \\
\text { (a) }\end{array}$ & $\begin{array}{l}\frac{\text { Second Stage of IV }}{\text { Model 1 }} \\
\text { Product improvement }\end{array}$ & $\begin{array}{l}\frac{\text { Second Stage of IV }}{\text { Model } 2} \\
\text { Campaign success }\end{array}$ \\
\hline Initial enhancement level & $\begin{array}{c}.074^{* * *} \\
(.005)\end{array}$ & $\begin{array}{c}.103^{* * *} \\
(.005)\end{array}$ & & $\begin{array}{c}.114^{* * *} \\
(.011)\end{array}$ & $\begin{array}{c}.147^{* * *} \\
(.011)\end{array}$ \\
\hline $\begin{array}{l}\text { Initial enhancement level } \times \\
\text { Initial enhancement level }\end{array}$ & $-.003 * * *$ & $-.003 * * *$ & & $-.003^{* * *}$ & $-.003^{* * *}$ \\
\hline & $(.000)$ & $(.000)$ & & $(.000)$ & $(.000)$ \\
\hline Competition & $\begin{array}{c}-1.189 * * * \\
(.257)\end{array}$ & $\begin{array}{c}-2.033 * * * \\
(.286)\end{array}$ & $\begin{array}{l}-2.338^{*} \\
(1.272)\end{array}$ & $\begin{array}{l}-.379 \\
(.317)\end{array}$ & $\begin{array}{c}-1.166 * * * \\
(.331)\end{array}$ \\
\hline Category: Technology & $\begin{array}{l}.022 \\
(.022)\end{array}$ & $\begin{array}{l}.033 \\
(.021)\end{array}$ & $\begin{array}{c}.693 * * * \\
(.095)\end{array}$ & $\begin{array}{l}-.007 \\
(.024)\end{array}$ & $\begin{array}{l}.003 \\
(.022)\end{array}$ \\
\hline Goal (ln) & $\begin{array}{l}-.007 \\
(.008)\end{array}$ & $\begin{array}{c}-.334 * * * \\
(.008)\end{array}$ & $\begin{array}{c}.534 * * * \\
(.031)\end{array}$ & $\begin{array}{c}-.027 * * * \\
(.009)\end{array}$ & $\begin{array}{c}-.356^{* * * *} \\
(.009)\end{array}$ \\
\hline Duration & $\begin{array}{c}.003^{* * * *} \\
(.001)\end{array}$ & $\begin{array}{l}-.002^{*} \\
(.001)\end{array}$ & $\begin{array}{c}-.018^{* * *} \\
(.004)\end{array}$ & $\begin{array}{c}.004 * * * \\
(.001)\end{array}$ & $\begin{array}{l}-.001 \\
(.001)\end{array}$ \\
\hline Videos & $\begin{array}{l}.002 \\
(.012)\end{array}$ & $\begin{array}{l}-.006 \\
(.012)\end{array}$ & $\begin{array}{l}.609 * * * \\
(.077)\end{array}$ & $\begin{array}{l}-.021 \\
(.014)\end{array}$ & $\begin{array}{l}-.03 * * \\
(.013)\end{array}$ \\
\hline Pictures & $\begin{array}{c}.012^{* * *} \\
(.001)\end{array}$ & $\begin{array}{c}.033^{* * * *} \\
(.001)\end{array}$ & $\begin{array}{c}.266^{* * * *} \\
(.005)\end{array}$ & $\begin{array}{l}.002 \\
(.003)\end{array}$ & $\begin{array}{l}.022 * * * \\
(.003)\end{array}$ \\
\hline Risk-section length & $\begin{array}{l}0 * * * \\
(.000)\end{array}$ & $\begin{array}{c}0^{* * *} \\
(.000)\end{array}$ & $\begin{array}{c}.013 * * * \\
(.001)\end{array}$ & $\begin{array}{c}0^{*} \\
(.000)\end{array}$ & $\begin{array}{c}0 * * \\
(.000)\end{array}$ \\
\hline Pledge price & $\begin{array}{c}0^{*} \\
(.000)\end{array}$ & $\begin{array}{l}0 * * * \\
(.000)\end{array}$ & $\begin{array}{c}0 \\
(.000)\end{array}$ & $\begin{array}{c}0^{*} \\
(.000)\end{array}$ & $\begin{array}{l}0 * * * \\
(.000)\end{array}$ \\
\hline Delivery time & $\begin{array}{c}(.000) \\
0 \\
(.002)\end{array}$ & $\begin{array}{c}-.005 * * \\
(.002)\end{array}$ & $\begin{array}{l}.008 \\
. .009)\end{array}$ & $\begin{array}{c}0 \\
(.002)\end{array}$ & $\begin{array}{l}-.005^{*} \\
(.002)\end{array}$ \\
\hline Creator experience & $\begin{array}{l}.009 \\
(.012)\end{array}$ & $\begin{array}{l}.256 * * * \\
(.023)\end{array}$ & $\begin{array}{l}.163 * * * \\
(.056)\end{array}$ & $\begin{array}{l}.008 \\
(.012)\end{array}$ & $\begin{array}{l}.258^{* * * *} \\
(.023)\end{array}$ \\
\hline Individual & $\begin{array}{c}-.155^{* * *} \\
(.021)\end{array}$ & $\begin{array}{c}-.359^{* * *} \\
(.02)\end{array}$ & $\begin{array}{l}-.097 \\
(.092)\end{array}$ & $\begin{array}{l}-.153^{* * *} \\
(.021)\end{array}$ & $\begin{array}{c}-.359^{* * *} \\
(.019)\end{array}$ \\
\hline Before relaxation of rules & & & $\begin{array}{c}3.245^{* * *} \\
(.132)\end{array}$ & & \\
\hline Residuals & & & & $\begin{array}{c}-.04 * * * \\
(.01)\end{array}$ & $\begin{array}{c}-.043^{* * *} \\
(.01)\end{array}$ \\
\hline Residuals $\times$ Residuals & & & & $\begin{array}{c}0 \\
(.000)\end{array}$ & $\begin{array}{l}.001^{* *} \\
(.000)\end{array}$ \\
\hline Constant & $\begin{array}{c}-1.028^{* * *} \\
(.08)\end{array}$ & $\begin{array}{c}2.192 * * * \\
(.075)\end{array}$ & $\begin{array}{c}-1.086^{* * *} \\
(.318)\end{array}$ & $\begin{array}{c}-1.138 * * * \\
(.085)\end{array}$ & $\begin{array}{c}2.078^{* * *} \\
(.082)\end{array}$ \\
\hline $\begin{array}{l}\text { Observations } \\
\text { pseudo } R^{2}\end{array}$ & $\begin{array}{c}18173 \\
.044\end{array}$ & $\begin{array}{c}18173 \\
.206\end{array}$ & $\begin{array}{c}18173 \\
.411\end{array}$ & $\begin{array}{c}18173 \\
.045\end{array}$ & $\begin{array}{c}18173 \\
.207\end{array}$ \\
\hline
\end{tabular}

Nonparametric bootstrap standard errors (100 replications) in parentheses.

*** $p<.01, * * p<.05, * p<.1$ 
Table EC.6 When the number of topics is set to 60 in LDA Model.

\begin{tabular}{|c|c|c|c|c|c|}
\hline & $\begin{array}{c}\text { Probit Model 1 } \\
\text { Product improvement }\end{array}$ & $\begin{array}{r}\text { Probit Model 2 } \\
\text { Campaign success }\end{array}$ & $\begin{array}{l}\text { First Stage of IV Models } \\
\frac{1 \text { and } 2}{\text { Initial enhancement level }}\end{array}$ & $\begin{array}{c}\frac{\text { Second Stage of IV }}{\text { Model } 1} \\
\text { Product improvement }\end{array}$ & $\begin{array}{l}\frac{\text { Second Stage of IV }}{\frac{\text { Model } 2}{\text { Campaign success }}} \\
\text { Con }\end{array}$ \\
\hline Initial enhancement level & $\begin{array}{c}.066^{* * *} \\
(.004)\end{array}$ & $\begin{array}{c}.073^{* * *} \\
(.004)\end{array}$ & & $\begin{array}{c}.095^{* * *} \\
(.008)\end{array}$ & $\begin{array}{c}.116^{* * *} \\
(.009)\end{array}$ \\
\hline $\begin{array}{l}\text { Initial enhancement level } \times \\
\text { Initial enhancement level }\end{array}$ & $-.002 * * *$ & $-.002 * * *$ & & $-.002 * * *$ & $-.002 * * *$ \\
\hline & $(.000)$ & $(.000)$ & & $(.000)$ & $(.000)$ \\
\hline Competition & $\begin{array}{c}-.944 * * * \\
(.257)\end{array}$ & $\begin{array}{l}-2.088^{* * * *} \\
\quad(.281)\end{array}$ & $\begin{array}{l}-2.833^{*} \\
(1.578)\end{array}$ & $\begin{array}{l}-.287 \\
(.313)\end{array}$ & $\begin{array}{c}-1.128 * * * \\
(.328)\end{array}$ \\
\hline Category: Technology & $\begin{array}{l}.017 \\
(.018)\end{array}$ & $\begin{array}{l}.019 \\
(.021)\end{array}$ & $\begin{array}{c}1.239 * * * \\
(.114)\end{array}$ & $\begin{array}{l}-.018 \\
(.021)\end{array}$ & $\begin{array}{l}-.031 \\
(.023)\end{array}$ \\
\hline Goal $(\ln )$ & $\begin{array}{l}-.008 \\
(.007)\end{array}$ & $\begin{array}{c}-.328 * * * \\
(.008)\end{array}$ & $\begin{array}{c}.608 * * * \\
(.037)\end{array}$ & $\begin{array}{c}-.025^{* * *} \\
(.009)\end{array}$ & $\begin{array}{c}-.352 * * * \\
(.009)\end{array}$ \\
\hline Duration & $\begin{array}{l}.003^{* * *} \\
(.001)\end{array}$ & $\begin{array}{l}-.002^{*} \\
(.001)\end{array}$ & $\begin{array}{c}-.022 * * * \\
(.005)\end{array}$ & $\begin{array}{c}.003^{* * *} \\
(.001)\end{array}$ & $\begin{array}{l}-.001 \\
(.001)\end{array}$ \\
\hline Videos & $\begin{array}{l}.014 \\
(.013)\end{array}$ & $\begin{array}{l}-.004 \\
(.012)\end{array}$ & $\begin{array}{c}.732 * * * \\
(.1)\end{array}$ & $\begin{array}{l}-.006 \\
(.015)\end{array}$ & $\begin{array}{c}-.032 * * \\
(.013)\end{array}$ \\
\hline Pictures & $\begin{array}{l}.013 * * * \\
(.001)\end{array}$ & $\begin{array}{c}.034 * * * \\
(.001)\end{array}$ & $\begin{array}{c}.319^{* * *} \\
(.006)\end{array}$ & $\begin{array}{l}.004 \\
(.002)\end{array}$ & $\begin{array}{c}.021^{* * *} \\
(.003)\end{array}$ \\
\hline Risk-section length & $\begin{array}{c}0^{* * *} \\
(.000)\end{array}$ & $\begin{array}{c}0^{* * *} \\
(.000)\end{array}$ & $\begin{array}{c}.016^{* * *} \\
(.001)\end{array}$ & $\begin{array}{c}0 \\
(.000)\end{array}$ & $\begin{array}{c}0^{* *} \\
(.000)\end{array}$ \\
\hline Pledge price & $\begin{array}{c}0 \\
(.000)\end{array}$ & $\begin{array}{l}0 * * * \\
(.000)\end{array}$ & $\begin{array}{l}0^{*} \\
(.000)\end{array}$ & $\begin{array}{c}0 \\
(.000)\end{array}$ & $\begin{array}{l}0^{* * *} \\
(.000)\end{array}$ \\
\hline Delivery time & $\begin{array}{l}.003 \\
(.002)\end{array}$ & $\begin{array}{c}-.005^{* *} \\
(.002)\end{array}$ & $\begin{array}{l}.016 \\
(.011)\end{array}$ & $\begin{array}{c}.002 \\
(.002)\end{array}$ & $\begin{array}{c}-.005^{* *} \\
(.002)\end{array}$ \\
\hline Creator experience & $\begin{array}{l}.016 \\
(.012)\end{array}$ & $\begin{array}{c}.259^{* * * *} \\
(.023)\end{array}$ & $\begin{array}{l}.199 * * * \\
(.068)\end{array}$ & $\begin{array}{l}.015 \\
(.012)\end{array}$ & $\begin{array}{l}.26 * * * \\
(.024)\end{array}$ \\
\hline Individual & $\begin{array}{c}-.143 * * * \\
(.027)\end{array}$ & $\begin{array}{c}-.357 * * * \\
(.02)\end{array}$ & $\begin{array}{l}.063 \\
(.115)\end{array}$ & $\begin{array}{c}-.146 * * * \\
(.027)\end{array}$ & $\begin{array}{c}-.364 * * * \\
(.02)\end{array}$ \\
\hline Before relaxation of rules & & & $\begin{array}{c}3.74 * * * \\
(.166)\end{array}$ & & \\
\hline Residuals & & & & $\begin{array}{c}-.028 * * * \\
(.007)\end{array}$ & $\begin{array}{c}-.041 * * * \\
(.008)\end{array}$ \\
\hline Residuals $\times$ Residuals & & & & $\begin{array}{c}0 * * \\
(.000)\end{array}$ & $\begin{array}{c}0 * * \\
(.000)\end{array}$ \\
\hline Constant & $\begin{array}{c}-1.035^{* * *} \\
(.083)\end{array}$ & $\begin{array}{l}2.309^{* * *} \\
(.074)\end{array}$ & $\begin{array}{c}-3.2^{* * *} \\
(.412)\end{array}$ & $\begin{array}{c}-1.071 * * * \\
\quad(.083)\end{array}$ & $\begin{array}{c}2.266^{* * *} \\
(.077)\end{array}$ \\
\hline $\begin{array}{l}\text { Observations } \\
\text { pseudo } R^{2}\end{array}$ & $\begin{array}{c}18173 \\
.061\end{array}$ & $\begin{array}{c}18173 \\
.201\end{array}$ & $\begin{array}{c}18173 \\
.391\end{array}$ & $\begin{array}{c}18173 \\
.062\end{array}$ & $\begin{array}{c}18173 \\
.203\end{array}$ \\
\hline
\end{tabular}

Table EC.7 When the threshold is set to 8 while counting the number of topics.

\begin{tabular}{|c|c|c|c|c|c|}
\hline & $\begin{array}{c}\text { Probit Model } 1 \\
\text { Product improvement }\end{array}$ & $\begin{array}{c}\text { Probit Model 2 } \\
\text { Campaign success }\end{array}$ & $\begin{array}{l}\text { First Stage of IV Models } \\
\frac{1 \text { and } 2}{\text { Initial enhancement level }}\end{array}$ & $\begin{array}{c}\frac{\text { Second Stage of IV }}{\text { Model } 1} \\
\text { Product improvement }\end{array}$ & $\begin{array}{l}\frac{\text { Second Stage of IV }}{\text { Model 2 }} \\
\text { Campaign success }\end{array}$ \\
\hline Initial enhancement level & $\begin{array}{c}.068^{* * * *} \\
(.004)\end{array}$ & $\begin{array}{c}.081^{* * *} \\
(.004)\end{array}$ & & $\begin{array}{c}.106^{* * *} \\
(.009)\end{array}$ & $\begin{array}{c}.116^{* * *} \\
(.009)\end{array}$ \\
\hline $\begin{array}{l}\text { Initial enhancement level } \times \\
\text { Initial enhancement level }\end{array}$ & $\begin{array}{c}-.002 * * * \\
(.000)\end{array}$ & $\begin{array}{c}-.002 * * * \\
(.000)\end{array}$ & & $\begin{array}{c}-.002 * * * \\
(.000)\end{array}$ & $\begin{array}{c}-.002 * * * \\
(.000)\end{array}$ \\
\hline Competition & $\begin{array}{l}-.983^{* * * *} \\
(.256)\end{array}$ & $\begin{array}{c}-2.021 * * * \\
(.287)\end{array}$ & $\begin{array}{c}-3.273^{* *} \\
(1.599)\end{array}$ & $\begin{array}{l}.036 \\
(.313)\end{array}$ & $\begin{array}{c}-1.131 * * * \\
(.33)\end{array}$ \\
\hline Category: Technology & $\begin{array}{l}.031 \\
(.02)\end{array}$ & $\begin{array}{l}.029 \\
(.021)\end{array}$ & $\begin{array}{c}1.026^{* * *} \\
(.118)\end{array}$ & $\begin{array}{l}-.012 \\
(.023)\end{array}$ & $\begin{array}{l}-.007 \\
(.022)\end{array}$ \\
\hline Goal (ln) & $\begin{array}{l}-.001 \\
(.007)\end{array}$ & $\begin{array}{c}-.335^{* * *} \\
(.008)\end{array}$ & $\begin{array}{c}.695^{* * *} \\
(.04)\end{array}$ & $\begin{array}{c}-.027 * * * \\
(.008)\end{array}$ & $\begin{array}{c}-.358 * * * \\
(.009)\end{array}$ \\
\hline Duration & $\begin{array}{l}.003^{* * * *} \\
(.001)\end{array}$ & $\begin{array}{l}-.002^{*} \\
(.001)\end{array}$ & $\begin{array}{c}-.021^{* * *} \\
(.006)\end{array}$ & $\begin{array}{c}.003^{* * * *} \\
(.001)\end{array}$ & $\begin{array}{l}-.001 \\
(.001)\end{array}$ \\
\hline Videos & $\begin{array}{l}.014 \\
(.011)\end{array}$ & $\begin{array}{l}-.007 \\
(.012)\end{array}$ & $\begin{array}{c}.777 * * * \\
(.095)\end{array}$ & $\begin{array}{l}-.015 \\
(.014)\end{array}$ & $\begin{array}{l}-.031^{* *} \\
(.013)\end{array}$ \\
\hline Pictures & $\begin{array}{l}.011^{* * *} \\
(.001)\end{array}$ & $\begin{array}{l}.033^{* * *} \\
(.001)\end{array}$ & $\begin{array}{l}.34 * * * \\
(.006)\end{array}$ & $\begin{array}{l}-.002 \\
(.003)\end{array}$ & $\begin{array}{l}.022 * * * \\
(.003)\end{array}$ \\
\hline Risk-section length & $\begin{array}{c}0^{* * *} \\
(.000)\end{array}$ & $\begin{array}{c}0^{* * *} \\
(.000)\end{array}$ & $\begin{array}{l}.017 * * * \\
(.002)\end{array}$ & $\begin{array}{c}0^{* *} \\
(.000)\end{array}$ & $\begin{array}{c}0^{* *} \\
(.000)\end{array}$ \\
\hline Pledge price & $\begin{array}{c}0 \\
(.000)\end{array}$ & $\begin{array}{l}0^{* * *} \\
(.000)\end{array}$ & $\begin{array}{c}0 \\
(.000)\end{array}$ & $\begin{array}{c}0 \\
(.000)\end{array}$ & $\begin{array}{l}0 * * * \\
(.000)\end{array}$ \\
\hline Delivery time & $\begin{array}{l}-.001 \\
(.002)\end{array}$ & $\begin{array}{l}-.005^{* *} \\
(.002)\end{array}$ & $\begin{array}{c}.01 \\
(.011)\end{array}$ & $\begin{array}{l}-.001 \\
(.002)\end{array}$ & $\begin{array}{c}-.005^{* *} \\
(.002)\end{array}$ \\
\hline Creator experience & $\begin{array}{l}.025^{* *} \\
(.012)\end{array}$ & $\begin{array}{c}.257^{* * * *} \\
(.022)\end{array}$ & $\begin{array}{c}.218^{* * * *} \\
(.071)\end{array}$ & $\begin{array}{l}.024^{*} \\
(.013)\end{array}$ & $\begin{array}{l}.258^{* * * *} \\
(.023)\end{array}$ \\
\hline Individual & $\begin{array}{c}-.172 * * * \\
(.022)\end{array}$ & $\begin{array}{c}-.358 * * * \\
(.02)\end{array}$ & $\begin{array}{l}-.109 \\
(.119)\end{array}$ & $\begin{array}{l}-.17 * * * \\
(.023)\end{array}$ & $\begin{array}{c}-.358 * * * \\
(.019)\end{array}$ \\
\hline Before relaxation of rules & & & $\begin{array}{c}4.031^{* * *} \\
(.163)\end{array}$ & & \\
\hline Residuals & & & & $\begin{array}{c}-.04 * * * \\
(.008)\end{array}$ & $\begin{array}{c}-.035^{* * *} * \\
(.008)\end{array}$ \\
\hline Residuals $\times$ Residuals & & & & $\begin{array}{c}0 \\
(.000)\end{array}$ & $\begin{array}{c}0 \\
(.000)\end{array}$ \\
\hline Constant & $\begin{array}{c}-1.076^{* * *} \\
\quad(.071)\end{array}$ & $\begin{array}{l}2.219 * * * \\
(.074)\end{array}$ & $\begin{array}{l}-1.928 * * * \\
(.404)\end{array}$ & $\begin{array}{l}-1.181 * * * \\
\quad(.077)\end{array}$ & $\begin{array}{l}2.126^{* * *} \\
(.08)\end{array}$ \\
\hline $\begin{array}{l}\text { Observations } \\
\text { pseudo } R^{2}\end{array}$ & $\begin{array}{c}18173 \\
051\end{array}$ & $\begin{array}{c}18173 \\
.206\end{array}$ & $\begin{array}{c}18173 \\
411\end{array}$ & $\begin{array}{c}18173 \\
053\end{array}$ & $\begin{array}{c}18173 \\
.207\end{array}$ \\
\hline
\end{tabular}

Nonparametric bootstrap standard errors (100 replications) in parentheses.

$* * * p<.01, * * p<.05, * p<.1$ 
Table EC.8 When the threshold is set to 12 while counting the number of topics.

\begin{tabular}{|c|c|c|c|c|c|}
\hline & $\begin{array}{c}\text { Probit Model 1 } \\
\text { Product improvement }\end{array}$ & $\begin{array}{r}\text { Probit Model 2 } \\
\text { Campaign success }\end{array}$ & $\begin{array}{l}\frac{\text { First Stage of IV Models }}{1 \text { and } 2} \\
\text { Initial enhancement level }\end{array}$ & $\begin{array}{c}\frac{\text { Second Stage of IV }}{\text { Model } 1} \\
\text { Product improvement }\end{array}$ & $\begin{array}{l}\frac{\text { Second Stage of IV }}{\text { Model } 2} \\
\text { Campaign success }\end{array}$ \\
\hline Initial enhancement level & $\begin{array}{c}.076^{* * *} \\
(.004)\end{array}$ & $\begin{array}{c}.092 * * * \\
(.005)\end{array}$ & & $\begin{array}{c}.123^{* * *} \\
(.01)\end{array}$ & $\begin{array}{c}.143^{* * *} \\
(.011)\end{array}$ \\
\hline $\begin{array}{l}\text { Initial enhancement level } \times \\
\text { Initial enhancement level }\end{array}$ & $-.002 * * *$ & $-.003 * * *$ & & $-.003 * * *$ & $-.003 * * *$ \\
\hline & $(.000)$ & $(.000)$ & $(.000)$ & $(.000)$ & $(.000)$ \\
\hline Competition & $\begin{array}{c}-.911 * * * \\
(.254)\end{array}$ & $\begin{array}{c}-2.079 * * * \\
(.282)\end{array}$ & $\begin{array}{l}-2.56^{* *} \\
(1.291)\end{array}$ & $\begin{array}{l}-.025 \\
(.311)\end{array}$ & $\begin{array}{c}-1.129 * * * \\
(.329)\end{array}$ \\
\hline Category: Technology & $\begin{array}{l}.009 \\
(.019)\end{array}$ & $\begin{array}{l}.019 \\
(.021)\end{array}$ & $\begin{array}{c}1.017^{* * *} \\
(.092)\end{array}$ & $\begin{array}{l}-.039^{*} \\
(.022)\end{array}$ & $\begin{array}{l}-.031 \\
(.023)\end{array}$ \\
\hline Goal $(\ln )$ & $\begin{array}{l}.001 \\
(.008)\end{array}$ & $\begin{array}{c}-.328 * * * \\
(.008)\end{array}$ & $\begin{array}{c}.495 * * * \\
(.031)\end{array}$ & $\begin{array}{l}-.02 * * \\
(.009)\end{array}$ & $\begin{array}{c}-.352 * * * \\
(.009)\end{array}$ \\
\hline Duration & $\begin{array}{l}.003^{* * *} \\
(.001)\end{array}$ & $\begin{array}{l}-.002^{*} \\
(.001)\end{array}$ & $\begin{array}{c}-.017 * * * \\
(.004)\end{array}$ & $\begin{array}{c}.004^{* * *} \\
(.001)\end{array}$ & $\begin{array}{l}-.001 \\
(.001)\end{array}$ \\
\hline Videos & $\begin{array}{l}.007 \\
(.012)\end{array}$ & $\begin{array}{l}-.004 \\
(.012)\end{array}$ & $\begin{array}{c}.613^{* * * *} \\
(.08)\end{array}$ & $\begin{array}{l}-.021 \\
(.014)\end{array}$ & $\begin{array}{c}-.032 * * \\
(.013)\end{array}$ \\
\hline Pictures & $\begin{array}{c}.012^{* * *} \\
(.001)\end{array}$ & $\begin{array}{c}.034^{* * *} \\
(.001)\end{array}$ & $\begin{array}{c}.262 * * * \\
(.005)\end{array}$ & $\begin{array}{l}.001 \\
(.003)\end{array}$ & $\begin{array}{c}.021^{* * *} \\
(.003)\end{array}$ \\
\hline Risk-section length & $\begin{array}{l}0 * * * \\
(.000)\end{array}$ & $\begin{array}{l}0 * * * \\
(.000)\end{array}$ & $\begin{array}{c}.013^{* * * *} \\
(.001)\end{array}$ & $\begin{array}{l}0 * * * \\
(.000)\end{array}$ & $\begin{array}{l}0 * * \\
(.000)\end{array}$ \\
\hline Pledge price & $\begin{array}{c}0 \\
(.000)\end{array}$ & $\begin{array}{l}0 * * * \\
(.000)\end{array}$ & $\begin{array}{c}0^{*} \\
(.000)\end{array}$ & $\begin{array}{c}0 \\
(.000)\end{array}$ & $\begin{array}{l}0 * * * \\
(.000)\end{array}$ \\
\hline Delivery time & $\begin{array}{l}.003 \\
(.002)\end{array}$ & $\begin{array}{c}-.005^{* *} \\
(.002)\end{array}$ & $\begin{array}{l}.01 \\
(.009)\end{array}$ & $\begin{array}{l}.003 \\
(.002)\end{array}$ & $\begin{array}{c}-.005 * * \\
(.002)\end{array}$ \\
\hline Creator experience & $\begin{array}{l}.018 \\
(.013)\end{array}$ & $\begin{array}{c}.258^{* * * *} \\
(.023)\end{array}$ & $\begin{array}{c}.187 * * * \\
(.055)\end{array}$ & $\begin{array}{l}.015 \\
(.013)\end{array}$ & $\begin{array}{l}.258^{* * *} \\
(.023)\end{array}$ \\
\hline Individual & $\begin{array}{c}-.14^{* * * *} \\
(.025)\end{array}$ & $\begin{array}{c}-.356^{* * *} \\
(.02)\end{array}$ & $\begin{array}{l}-.003 \\
(.098)\end{array}$ & $\begin{array}{c}-.142 * * * \\
(.025)\end{array}$ & $\begin{array}{c}-.36 * * * \\
(.02)\end{array}$ \\
\hline Before relaxation of rules & & & $\begin{array}{c}3.043^{* * *} \\
(.139)\end{array}$ & & \\
\hline Residuals & & & & $\begin{array}{c}-.046 * * * \\
(.009)\end{array}$ & $\begin{array}{c}-.049 * * * \\
(.01)\end{array}$ \\
\hline Residuals $\times$ Residuals & & & & $\begin{array}{l}.001^{*} \\
(.000)\end{array}$ & $\begin{array}{l}.001^{* *} \\
(.000)\end{array}$ \\
\hline Constant & $\begin{array}{c}-1.156^{* * *} \\
(.092)\end{array}$ & $\begin{array}{c}2.295^{* * *} \\
(.074)\end{array}$ & $\begin{array}{c}-2.364 * * * \\
(.347)\end{array}$ & $\begin{array}{c}-1.213^{* * *} * \\
(.094)\end{array}$ & $\begin{array}{c}2.241^{* * *} \\
(.077)\end{array}$ \\
\hline $\begin{array}{l}\text { Observations } \\
\text { pseudo } R^{2}\end{array}$ & $\begin{array}{c}18173 \\
.056\end{array}$ & $\begin{array}{c}18173 \\
.203\end{array}$ & $\begin{array}{c}18173 \\
.389\end{array}$ & $\begin{array}{c}18173 \\
.057\end{array}$ & $\begin{array}{c}18173 \\
.204\end{array}$ \\
\hline
\end{tabular}

Table EC.9 Control for competition in the first week of each campaign.

\begin{tabular}{|c|c|c|c|}
\hline & $\frac{\text { Probit Model } 1}{\text { Prot }}$ & First Stage of IV Model 1 & Second Stage of IV Model 1 \\
\hline & Product improvement & & \\
\hline Initial enhancement level & $\begin{array}{l}.072^{* * *} \\
(.004)\end{array}$ & & $\begin{array}{l}.104^{* * *} \\
(.009)\end{array}$ \\
\hline $\begin{array}{l}\text { Initial enhancement level } \times \\
\text { Initial enhancement level }\end{array}$ & $-.002 * * *$ & & $-.002 * * *$ \\
\hline & $(.000)$ & & $(.000)$ \\
\hline Competition & $\begin{array}{c}-.996^{* * *} \\
(.238)\end{array}$ & $\begin{array}{c}-2.614 * * \\
(1.293)\end{array}$ & $\begin{array}{l}-.499^{*} \\
(.277)\end{array}$ \\
\hline Category: Technology & $\begin{array}{l}.053 * * \\
(.023)\end{array}$ & $\begin{array}{c}1.003 * * * \\
(.103)\end{array}$ & $\begin{array}{l}.023 \\
(.025)\end{array}$ \\
\hline Goal $(\ln )$ & $\begin{array}{l}-.006 \\
(.008)\end{array}$ & $\begin{array}{l}.58 * * * \\
(.034)\end{array}$ & $\begin{array}{c}-.024 * * * \\
(.009)\end{array}$ \\
\hline Duration & $\begin{array}{c}.003^{* * *} \\
(.001)\end{array}$ & $\begin{array}{c}-.019 * * * \\
(.005)\end{array}$ & $\begin{array}{c}.003 * * * \\
(.001)\end{array}$ \\
\hline Videos & $\begin{array}{l}.014 \\
(.012)\end{array}$ & $\begin{array}{c}.697 * * * \\
(.089)\end{array}$ & $\begin{array}{l}-.007 \\
(.014)\end{array}$ \\
\hline Pictures & $\begin{array}{c}.013 * * * \\
(.001)\end{array}$ & $\begin{array}{l}.296^{* * *} \\
(.006)\end{array}$ & $\begin{array}{l}.003 \\
(.003)\end{array}$ \\
\hline Risk-section length & $\begin{array}{l}0^{* * *} \\
(.000)\end{array}$ & $\begin{array}{c}.015 * * * \\
(.001)\end{array}$ & $\begin{array}{c}0 \\
(.000)\end{array}$ \\
\hline Pledge price & $\begin{array}{c}0 \\
(.000)\end{array}$ & $\begin{array}{c}0 \\
(.000)\end{array}$ & $\begin{array}{c}0 \\
(.000)\end{array}$ \\
\hline Delivery time & $\begin{array}{l}.002 \\
(.002)\end{array}$ & $\begin{array}{l}.011 \\
(.01)\end{array}$ & $\begin{array}{l}.002 \\
(.002)\end{array}$ \\
\hline Creator experience & $\begin{array}{c}.02 \\
(.015)\end{array}$ & $\begin{array}{c}.203 * * * \\
(.062)\end{array}$ & $\begin{array}{l}.018 \\
(.015)\end{array}$ \\
\hline Individual & $\begin{array}{c}-.139 * * * \\
(.024)\end{array}$ & $\begin{array}{l}-.037 \\
(.107)\end{array}$ & $\begin{array}{c}-.14 * * * \\
(.024)\end{array}$ \\
\hline Before relaxation of rules & & $\begin{array}{c}3.51 * * * \\
(.15)\end{array}$ & \\
\hline Residuals & & & $\begin{array}{c}-.032 * * * \\
(.008)\end{array}$ \\
\hline Residuals $\times$ Residuals & & & $\begin{array}{c}0 \\
(.000)\end{array}$ \\
\hline Constant & $\begin{array}{l}-1.082^{* * *} \\
\quad(.085)\end{array}$ & $\begin{array}{l}-2.277 * * * \\
(.348)\end{array}$ & $\begin{array}{c}-1.107 * * * \\
(.086)\end{array}$ \\
\hline Observations & 18173 & 18173 & 18173 \\
\hline pseudo $R^{2}$ & .056 & .399 & .057 \\
\hline
\end{tabular}

